bioRxiv preprint doi: https:/doi.org/10.1101/2021.06.26.450022; this version posted June 29, 2021. The copyright holder for this preprint (which was not certified by peer review) is the author/funder, who has granted bioRxiv a license to display the preprint in perpetuity. It is made available under aCC-BY-NC-ND 4.0 International license.

\title{
Snail maintains the stem/progenitor state of skin epithelial cells and carcinomas through the autocrine effect of the matricellular protein Mindin
}

Krithika Badarinath¹, Binita Dam², Sunny Kataria', Ravindra K. Zirmire',3, Rakesh Dey², Randhir Singh" ${ }^{4}$, Tafheem A. Masudi2, \#, Janani Sambath5,6, Prashanth Kumar ${ }^{5,6,7}$, Akash Gulyani, @, You-Wen $\mathrm{He}^{8}$, Sudhir Krishna ${ }^{1}$ and Colin Jamora ${ }^{2}$.

1. National Centre for Biological Sciences (TIFR), Bangalore, Karnataka 560065, India

2. IFOM-inStem Joint Research Laboratory, Centre for Inflammation and Tissue Homeostasis, Institute for Stem Cell Science and Regenerative Medicine (inStem), Bangalore, Karnataka 560065, India

3. Shanmugha Arts, Science, Technology and Research Academy (SASTRA) University, Thanjavur 613401, Tamil Nadu, India

4. Integrative Chemical Biology, Institute for Stem Cell Science and Regenerative Medicine (inStem), Bangalore, Karnataka 560065, India

5. Institute of Bioinformatics, International Technology Park, Bengaluru, 560066, Karnataka, India

6. Manipal Academy of Higher Education (MAHE), Manipal, 576104, Karnataka, India

7. Somaiya Institute of Research and Consultancy (SIRAC), Somaiya Vidyavihar University (SVU), Vidyavihar, Mumbai, 400077, Maharashtra, India

8. Department of Immunology, Duke University Medical University Medical Center, Durham, NC

\#Current address: Department of Medical Biochemistry and Cell Biology, Institute of Biomedicine at the Sahlgrenska Academy, University of Gothenburg, 41390, Gothenburg, Sweden

@ Current address: Department of Biochemistry, School of Life Sciences, University of Hyderabad, Central University Post, Prof. C.R. Rao, Gachibowli, Hyderabad, Telengana 500046, India

*Corresponding author: colinj@instem.res.in

\section{Summary}

Intratumoral heterogeneity poses a major challenge in designing effective anti-cancer strategies. Accumulating evidence suggests that this heterogeneity arises from cancer stem cells (CSCs) that also drives tumor aggressiveness and drug resistance. The stemness of CSCs are preserved by an ill-defined combination of intrinsic and external factors and is particularly intriguing since they exist within a sea of similar cells at various degrees of differentiation. In models of cutaneous squamous cell carcinoma (CSCC), we discovered a non-EMT function for the transcription factor Snail in maintaining stemness of keratinocytes. This is accomplished by the secretion of the matricellular protein Mindin from Snail expressing cells, which creates a protective niche that impedes differentiation. In an autocrine fashion, extracellular Mindin activates a Src-STAT3 pathway to reinforce the stem/progenitor phenotype and disruption of this signalling module in human cSCC attenuates tumorigenesis. The expression of Mindin in multiple carcinomas, and its critical role in cancer progression suggests that it would be a promising target for therapeutic intervention.

\section{Key words}

Tumor heterogeneity, Cancer stem cells, Snail, EMT, Mindin, SFK, STAT3 
bioRxiv preprint doi: https://doi org/10.1101/2021.06.26.450022: this version posted June 29,2021 . The copyright holder for this preprint

\section{Introduction}

Intratumoral heterogeneity, is a term to describe the diversification of both the non-malignant and malignant compartments of the tumor. The former is a local microenvironment, also known as the stroma, that is composed of different cell populations including fibroblasts, endothelial cells, and immune cells. There is burgeoning interest in the role of the tumor stroma which has a profound impact on a wide spectrum of tumorigenic processes ranging from metastasis (Guo and Deng, 2018) to therapeutic resistance (Straussman et al., 2012). Another aspect of heterogeneity arises among the malignant epithelial cells that comprise the tumor mass. These epithelial cells differ in their growth rates, tumorigenic potential, and differentiation status and are driven by alterations in their DNA sequence, epigenome, transcriptome, proteome, and metabolome (Somasundaram et al., 2012). A plethora of studies suggest that intratumor heterogeneity is also a leading determinant of treatment failure and poor overall survival of cancer patients, and is thus the subject of intense research from a biological as well as a treatment point of view. (Michor and Polyak, 2010; Somasundaram et al., 2012; Tellez-Gabriel et al., 2016).

A prominent model to explain the manifestation of intratumor heterogeneity is the cancer stem cell (CSC) concept introduced in the late 1990's (Lapidot et al., 1994). The CSC hypothesis posits that the tumor is a hierarchically organised tissue wherein these tumor initiating cells generate the various types of differentiated cells of the tumor mass. Similar to normal somatic stem cells, CSCs are distinguished by their capacity for indefinite selfrenewal, which positions them as a central player in cancer initiation, maintenance, and progression. Interestingly, the CSC population is not static but increases in number with tumor grade thereby increasing tumor heterogeneity (Li et al., 2013; Yu, 2012). Moreover, CSCs are usually quiescent, have increased proficiency in DNA repair, disable their apoptotic pathways, and express increased levels of efflux transporters (Phi et al., 2018). These characteristics render CSCs capable of evading standard cytotoxic therapies (Li et al., 2021). Another similarity with tissue stem cells is the residence of CSCs within a niche. This niche is a specialized microenvironment that regulates stem cell behaviour by providing cues in the form of both cellular contacts and soluble factors (Sun et al., 2019). These soluble factors can arise from the tumor cell itself as well as from cells in the tumor stroma (Plaks et al., 2015). Examples of growth factors and cytokines that maintain the undifferentiated state of cells are Hedgehog, Wnt, and Notch, while stemness-promoting intracellular signalling pathways utilize JAK/STAT, PI3K/phosphatase, Hippo and NF-kB (Matsui, 2016; Plaks et al., 2015).

Given the importance of CSCs, many studies have focused on understanding their role and regulation in tumorigenesis. One open question is how are the few CSCs maintained in a tumor mass amongst a sea of differentiating cells. To answer this question, we utilized a transgenic mouse model based on the overexpression of Snail in epidermal keratinocytes (K14-Snail Tg), which reproduces many of the cardinal features of squamous cell carcinoma (Du et al., 2010). Snail, is a transcription factor that is well known for its function in inducing an epithelial-mesenchymal transition (EMT) during embryogenesis (Murray and Gridley, 2006) and hair morphogenesis (Jamora et al., 2005), and is overexpressed in many carcinomas (Fan et al., 2012a; Goossens et al., 2017; Mani et al., 2009). Interestingly, there is a strong correlation between Snail expression with the number of CSCs (Hojo et al., 2018a; Ma et al., 2017; Zhou et al., 2014) as well as tumor aggressiveness (Smith et al., 2014; Zheng et al., 2015). Several proposals have been formulated to explain the connection between Snail and CSCs including the ability of EMTs to promote dedifferentiation of cells to acquire stem cell properties (Wang and Unternaehrer, 2019). Moreover, extracellular signals such as TGF $\beta$ and Wnt, that are known to promote CSC 
production, are dependent on EMT drivers such as Snail and Twist (Scheel et al., 2011). Despite these correlations, the molecular mechanism by which Snail specifically regulates the stemness and number of CSCs remains largely unknown.

\section{Results}

\section{Overexpression of Snail reinforces the stem/progenitor characteristics in epidermal keratinocytes in vitro}

Given Snail's canonical function in inducing an EMT, we tested if this process was activated in the K14-Snail transgenic (Snail Tg) skin by three different criteria: 1) lineage tracing assay (Tan et al., manuscript in preparation), 2) immunofluorescence to examine cells coexpressing markers of the epithelial (keratin 5) and mesenchymal cells (vimentin [Figure 1A] and collagen [Figure S1A]) and 3) maintenance of distinct epithelial and mesenchymal compartments delineated by the basement membrane marked by laminin 5 (Figure 1A). Altogether, this analysis unexpectedly revealed that transgenic expression of Snail in normal epidermal keratinocytes in vivo is insufficient to induce an EMT. To validate these surprising observations, we examined whether primary keratinocytes isolated from the Snail Tg skin exhibited features of EMT in vitro. We computed the EMT score for each sample using transcriptome data to estimate the EMT phenotype (Tan et al., 2014) (Figure 1B). The EMT scores of both wild type and Snail Tg cells were distributed between -0.18 to -0.20 indicating that the EMT status did not differ between the samples (Figure S1B), and both cell populations are epithelial in nature. Consistent with the in vivo data, primary keratinocytes isolated from the Snail Tg skin retain their epithelial characteristics in vitro.

We previously observed that the Snail Tg skin recapitulated many hallmarks of cutaneous squamous cell carcinoma (Du et al., 2010). In particular, there was robust epidermal hyperplasia with an expansion of the basal layer (Du et al., 2010), which harbours the stem/progenitor cells of the epidermis. To determine how Snail is stimulating the expansion of the basal layer of keratinocytes (Du et al., 2010) in an non-EMT fashion, we analysed the transcriptome profile of the transgenic keratinocytes for potential clues. Gene ontology of differentially expressed genes (Figure S1C) revealed that the regulation of cell proliferation and cell differentiation are the top two biological processes that are affected in the Snail Tg keratinocytes (Figure 1C). qPCR analysis confirmed that there was elevated levels of proliferation associated genes and decreased expression of differentiation genes in Snail Tg keratinocytes (Figure 1D). Thus, the underlying expansion of the basal layer of the Snail Tg skin may be accomplished by the hyperproliferation of keratinocytes, and/or the inhibition of differentiation. Interestingly, we found that primary Snail Tg keratinocytes do not display a higher proliferation rate in vitro compared to wild type cells (Figure S1D). This is consistent with our previous report that implicated inflammation as the inducer of epidermal keratinocyte proliferation in vivo (Du et al., 2010). Interestingly, the transcriptome of the transgenic cells indicates that genes involved in stem cell population maintenance are upregulated (Figure 1E and Figure S1E). One prediction that can be made if Snail maintains the stem/progenitor characteristic of basal epidermal keratinocytes, is that there should be resistance to the chemical induction of differentiation. To test this, we inspected the differentiation potential of Snail Tg keratinocytes in vitro by the classical calcium switch assay (Bikle et al., 2012). Differentiation genes such as involucrin and loricrin are lower in 
bioRxiv preprint doi: https://doi.org/10.1101/2021.06.26.450022; this version posted June 29, 2021. The copyright holder for this preprint (which was not certified by peer review) is the author/funder, who has granted bioRxiv a license to display the preprint in perpetuity. It is made available under aCC-BY-NC-ND 4.0 International license.

the Snail Tg keratinocytes compared to WT cells (Figure 1F and Figure S1F). This is consistent with our previous study which reports that the Snail Tg epidermis exhibits a spatial delay in the differentiation process (Jamora et al., 2005). In total, these results reveal a novel non EMT function of Snail in maintaining stem/progenitor characteristics in epidermal keratinocytes of the basal layer.

A
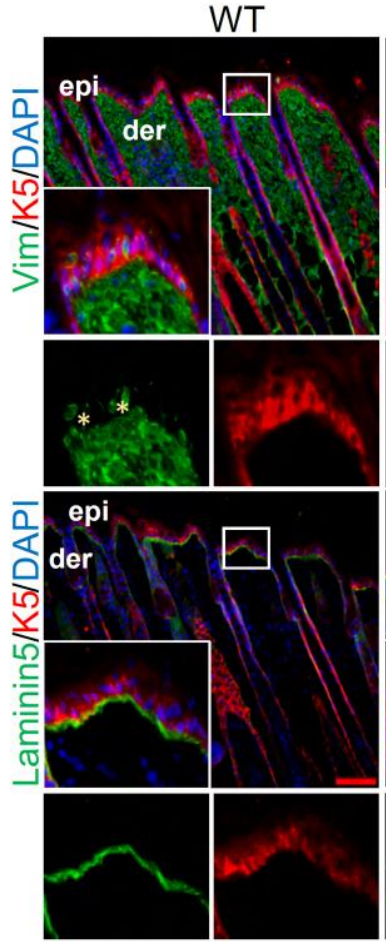

B

C

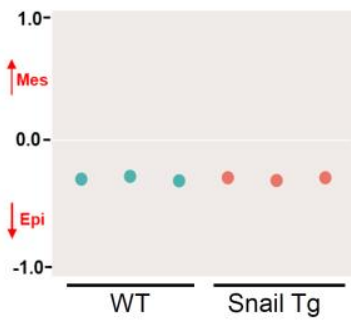

Gene Ontology (Biological processes)

Regulation of cell proliferation Regulation of cell differentiation Blood vessel development Cell-substrate adhesion Cell migration Lymphocyte activation Response to wound healing Epithelial cell proliferation
Snail Tg

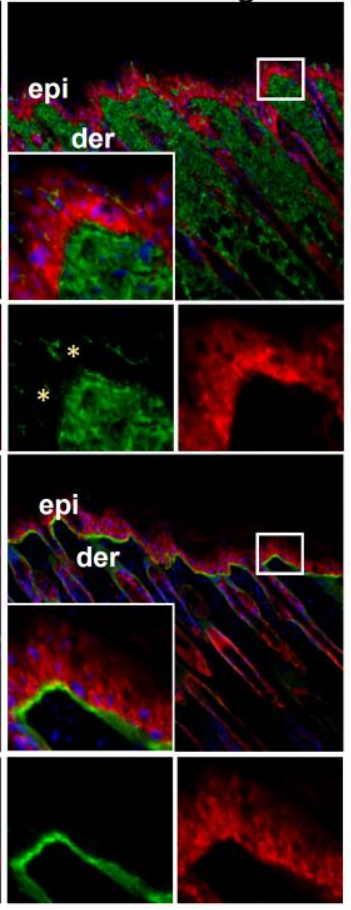

D
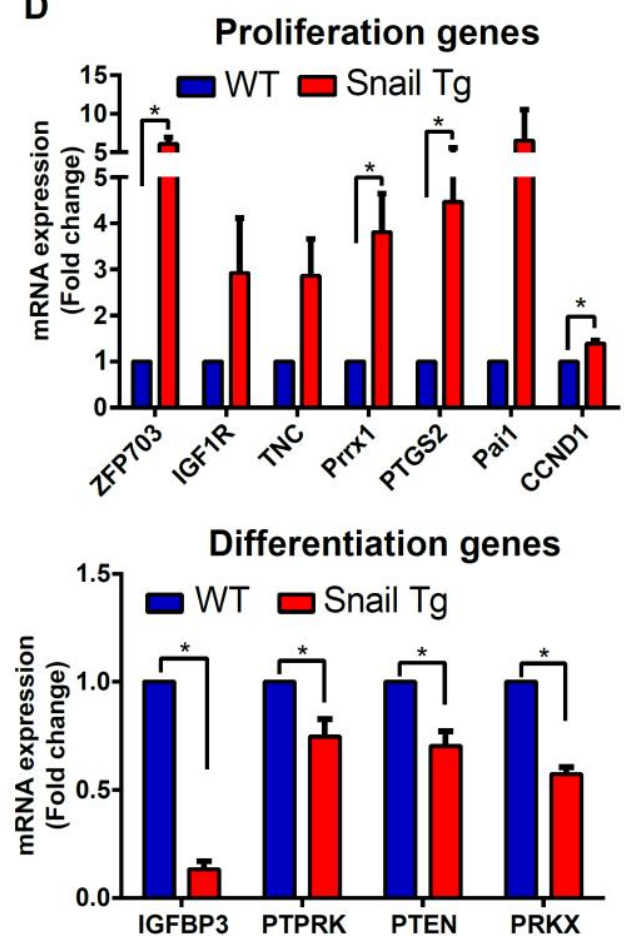

\section{E} Stem Cell Population Maintenance
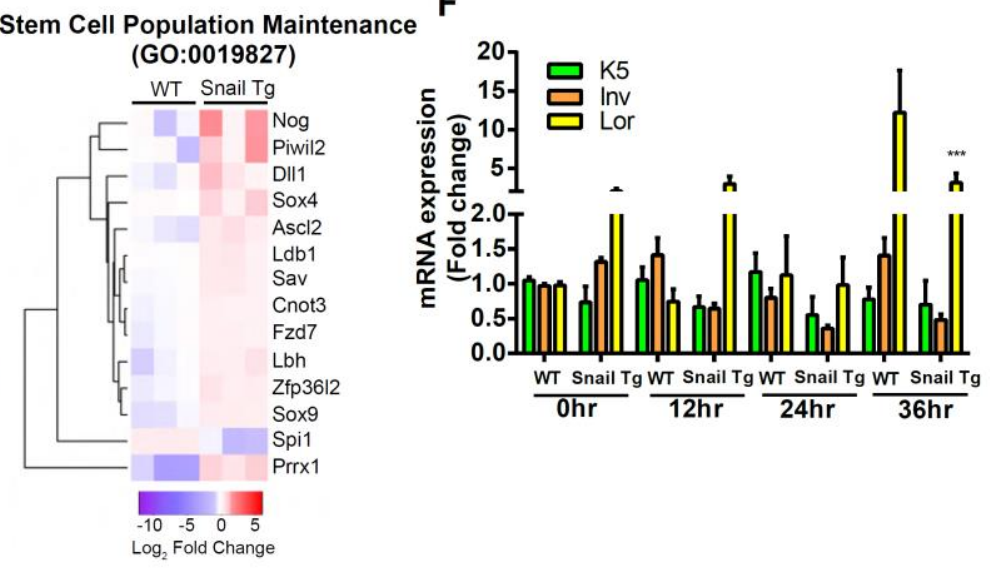

Figure 1: Overexpression of Snail reinforces the stem/progenitor characteristics in vitro.

(A) Immunofluorescence assay representing intact compartmentalization of cells in the skin. Top row: Vimentin (green) to mark the mesenchymal cells, Keratin 5 (red) to mark the basal epidermal keratinocytes and outer root sheath of hair follicles in wild type (WT) and Snail transgenic ( $\mathrm{Tg}$ ) skin. Bottom row: Laminin 5 (green) marks the basal lamina and keratin 5 (red) marks the basal epidermal keratinocytes. Insets in each panel are magnified views of the boxed areas of the epidermis. Scale bar: $50 \mu \mathrm{m}$.

(B) EMT score calculated using the transcriptome data of WT and Snail Tg keratinocytes.

(C) Gene ontology of the differentially expressed genes in Snail Tg keratinocytes.

(D) qPCR of proliferation and differentiation associated genes $(n=3)$.

(E) Heat map of genes corresponding to the GO term: stem cell population maintenance.

(F) qPCR analysis of differentiation potential of WT and Snail transgenic keratinocytes in the calcium switch assay ( $n=3)$.

Error bars depict \pm SEM. ${ }^{*} P<0.05,{ }^{\star \star *} P<0.001$. See also Figure $S 1$. 
bioRxiv preprint doi: https:/doi.org/10.1101/2021.06.26.450022; this version posted June 29, 2021. The copyright holder for this preprint

\section{Epidermal Snail expression expands the epidermal stem/progenitor cell population in vivo}

To investigate whether the epidermal hyperplasia in the Snail Tg skin (Du et al., 2010) is due to the expanded number of epidermal stem/progenitors cells, we analysed two widely utilized markers of these cells - CD49f (Krebsbach and Villa-Diaz, 2017; Schober and Fuchs, 2011; Ye et al., 2017) and p63 (Blanpain and Fuchs, 2007; Koster et al., 2005).

Immunohistochemical analysis of these markers showed an increase in the Snail Tg epidermis compared to its WT counterpart (Figure 2A). These results were intriguing since the basal layer (marked by Keratin 5 ) is the exclusive home of the epidermal stem/progenitor cells and their delamination from this layer to the suprabasal layer is generally considered a signal to lose their stemness and enter the terminal differentiation program (Fuchs, 2008). We found that there is a substantial increase in the number of p63 positive cells in the suprabasal layers of the Snail Tg epidermis (Figure S2A). In addition, generic markers of stem cells such as Oct4, Sox2 and Nanog were likewise upregulated in the Snail Tg skin (Figure S2B). Furthermore, ultrastructural analysis of the suprabasal keratinocytes of the epidermis in the Snail Tg skin revealed pleomorphic nuclei with diffused heterochromatin and multiple nucleoli, which are morphological features of stem cells (Figure 2B).

Given the expansion of the epidermal stem/progenitor cells found in vivo, we investigated whether this phenotype is a cell autonomous effect of Snail overexpression or secondary to inflammation (Du et al., 2010). To probe the cell autonomous function of Snail, we cultured primary keratinocytes from WT and Snail Tg skin and analysed various characteristics of stemness. In colony forming assays, which scores for the self-renewal capacity of stem cells, Snail Tg keratinocytes exhibited a higher number of colonies over several seedings compared to WT cells (Figure 2C). Other features of CSCs such as increased nuclear to cytoplasmic ratio (Yang et al., 2020) (Figure 2D), and expression of stem cell genes (Figure 2E) are higher in Snail Tg keratinocyte relative to its WT counterpart. These observations are consistent with reports of a strong positive correlation between Snail expression and the undifferentiated state of cancer cells (Fan et al., 2012a; Ma et al., 2017). Our in vitro findings were further validated using a xenograft assay, which is the gold standard in defining a cell as a stem cell. We grafted $0.25 \times 10^{6}$ Snail Tg keratinocytes in NSG animals with WT cells as control. Two months post grafting, $\sim 90 \%$ of mice formed tumors with Snail Tg keratinocytes compared to $0 \%$ with control cells (Figure $2 \mathrm{~F}$ ). Interestingly, when we serially grafted the cells isolated from the first graft ( $1^{\text {st }}$ generation) of Snail Tg tumors, we observed that $\sim 75 \%$ of the grafts formed 2 nd generation tumors. These results suggest that Snail overexpression not only upregulates markers associated with stem/progenitor cells, but it also endows them stem cell capabilities. 
A

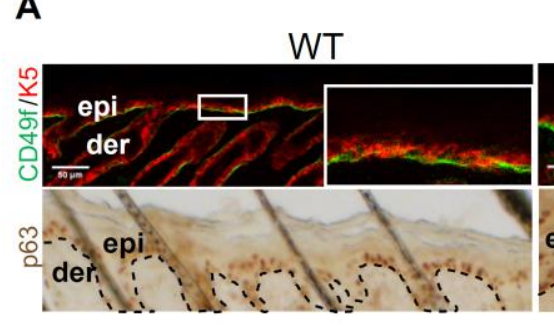

B
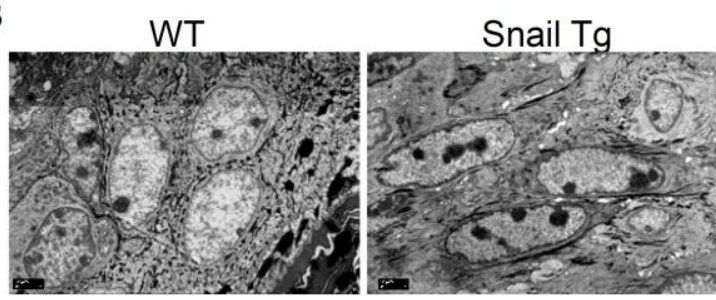

D
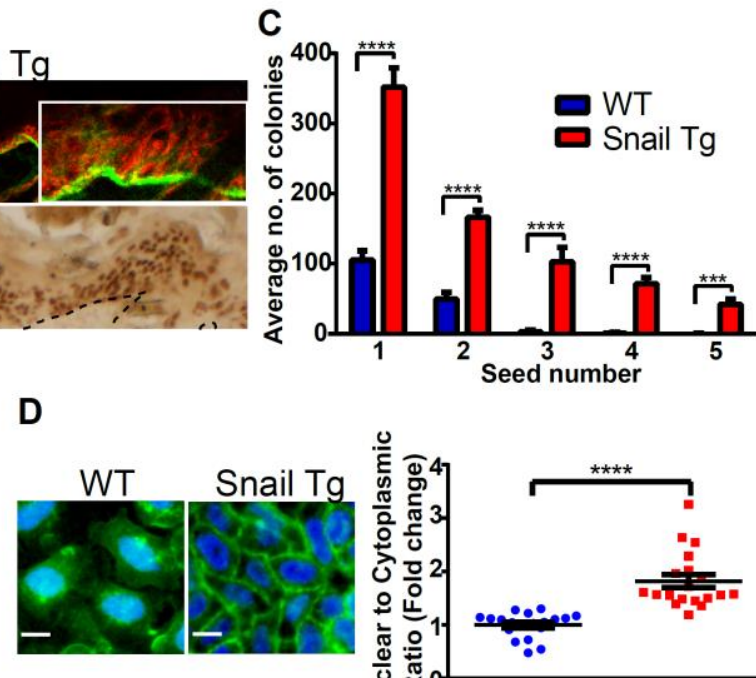

E

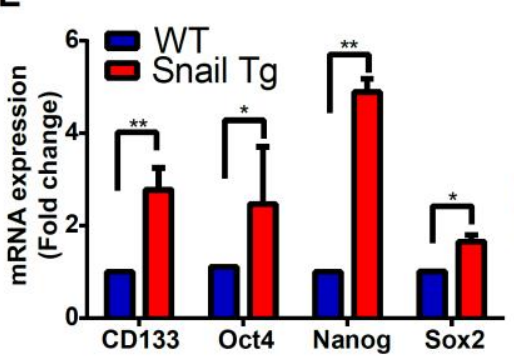

$\mathbf{F}$

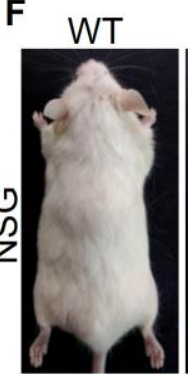

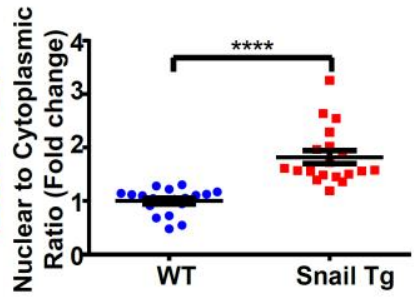

Figure 2. Epidermal Snail expression expands the epidermal stem/progenitor cell population in vivo.

(A) Immunohistochemistry of CD49f and p63 marking the stem/progenitor cells in WT and Snail Tg skin.

Dotted line represents the basement membrane, which separates the epidermis (epi) from the underlying dermis (der).

Scale bar: $50 \mu \mathrm{m}$

(B) Ultrastructure analysis demonstrating increased number of nucleoli and dispersed chromatin in the nucleoplasm of Snail Tg suprabasal keratinocytes compared to its WT counterpart $(n=2)$. Scale bar: $2 \mu \mathrm{m}$

(C) Colony formation assay performed on WT and Snail Tg keratinocytes. 1000 cells were plated per well for each seeding and number of colonies were quantified seven days post seeding ( $n=3 /$ seeding)

(D) Analysis of nuclear to cytoplasmic ratio in WT and Snail Tg epidermal keratinocytes. Left panels: Immunofluorescence of WGA to mark the cell membrane and DAPI to mark the nucleus. Scale bar: $5 \mu \mathrm{m}$ Right panel: Quantification showing higher nuclear to cytoplasmic ratio of Snail Tg keratinocytes compared to WT cells.

(E) WT (blue) and Snail Tg (red) keratinocytes analysed for the stem cell genes CD133, Oct4, Sox2, and Nanog by qPCR ( $n=3$ ). (F) Tumor forming capacity of WT and Snail Tg keratinocytes injected in NSG animals. Image shows tumour formed by the Snail Tg keratinocytes at the flank region two months post injection. Scale bar: $5 \mathrm{~mm}$. The table summarizes the number of tumours formed by WT and Snail Tg cells in the initial injection and the 1st generation derived from cells from the tumor developed in the initial injection.

Error bars depict \pm SEM. ${ }^{*} P<0.05,{ }^{* *} P<0.01,{ }^{* * *} P<0.001$ and ${ }^{* * * *} P<0.0001$. See also Figure S2.

\section{Snail mediated stem/progenitor cell maintenance is dependent upon STAT3 activation}

While many studies have firmly established an association of Snail expression with heightened cancer stem like properties (De Craene et al., 2014; Hojo et al., 2018a), the mechanism underlying this correlation nevertheless remains elusive. An essential component that maintains the stemness of a variety of cells is the active form of STAT3 (phosphorylated STAT3)(Galoczova et al., 2018; Raz et al., 1999). Previously, we had shown that there is increased activation of STAT3 in the Snail Tg compared to the WT epidermis (Du et al., 2010). The activation of STAT3 was also observed in cultured Snail Tg keratinocytes (Figure 3A-B and Figure S3A-B). To determine the functional relevance of this 
activated STAT3, we treated WT and Snail Tg keratinocytes with BP-1-102, a small molecule inhibitor, which inhibits the phosphorylation, dimerization, and subsequent nuclear translocation of STAT3 (Zhang et al., 2012). We found that inhibition of STAT3 activity by $\sim 50 \%$ in Snail transgenic keratinocytes (Figure S3C-D) substantially suppressed their selfrenewal capacity (Figure 3C) and stem cell associated genes (Figure 3D). In addition, the increased nuclear to cytoplasmic ratio (NCR) and the expression of the cancer stem cell marker CD44 (Figure 3E-F and Figure S3E) were significantly reduced to near WT levels upon STAT3 inhibition.

We extended this study to understand if STAT3 activation was essential for Snail's impact on keratinocyte stemness in vivo. The STAT3 inhibitor was applied topically on the back skin of newborn WT and Tg animals every two days up to day 7. Analysis of the skin revealed that the increase in the number of layers positive for keratin 5 in the Snail Tg epidermis was significantly reduced upon STAT3 inhibition (Figure 3G-H). Further we found that the reduction of the thickened basal layer correlated with a decrease in the number of p63+ stem/progenitor cells (Figure $3 \mathrm{I}$ and S3F). Collectively, both in vitro and in vivo studies indicate that the activation of STAT3 is crucial for Snail mediated stem/progenitor characteristics of epidermal keratinocytes. 
bioRxiv preprint doi: https://doi.org/10.1101/2021.06.26.450022; this version posted June 29, 2021. The copyright holder for this preprint (which was not certified by peer review) is the author/funder, who has granted bioRxiv a license to display the preprint in perpetuity. It is made available under aCC-BY-NC-ND 4.0 International license.

A
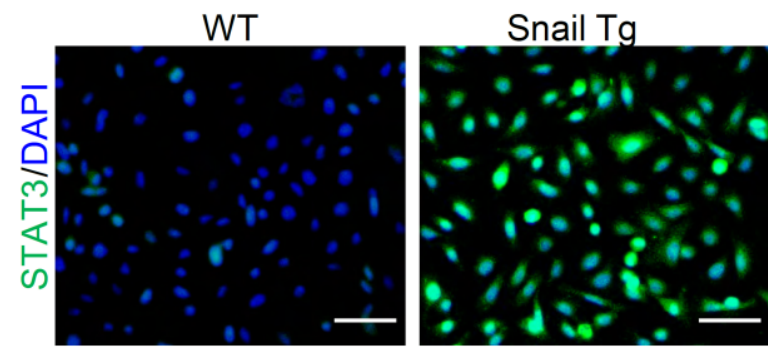

B

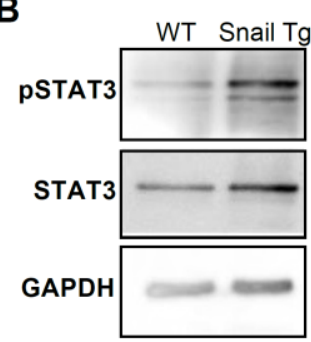

$\mathbf{F}$

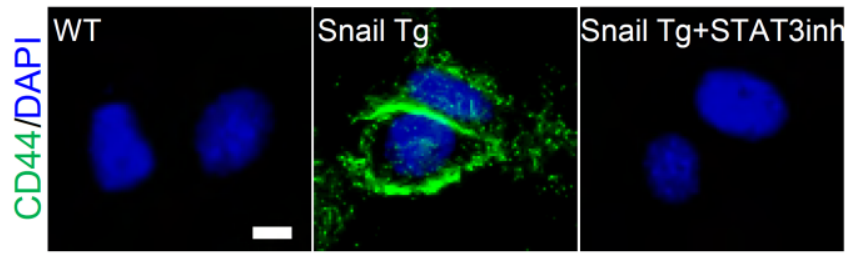

G

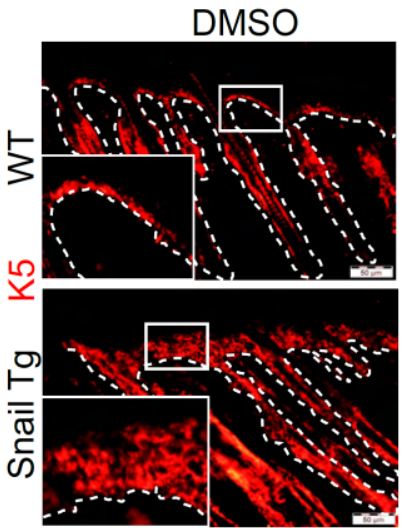

D

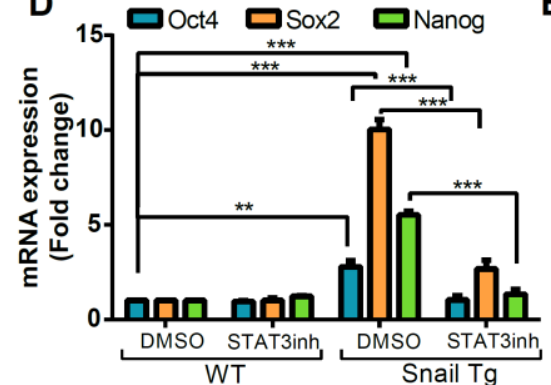

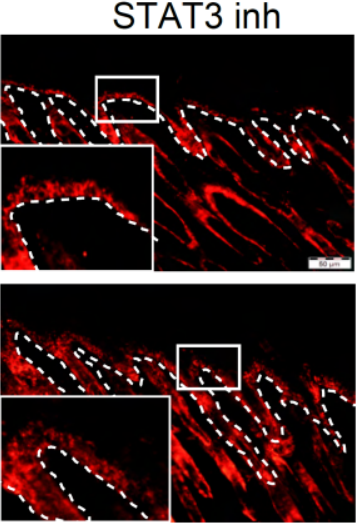

C

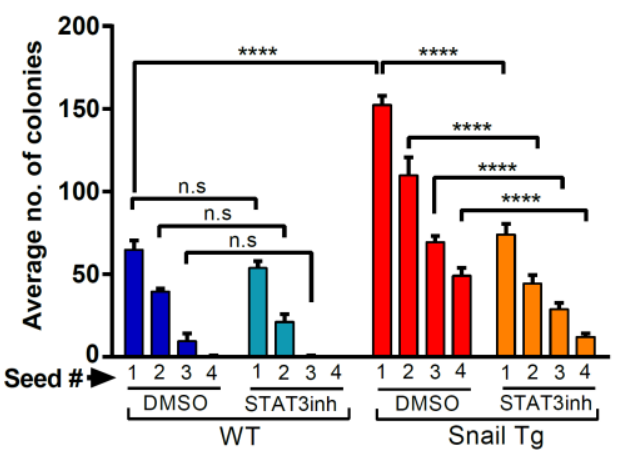

E

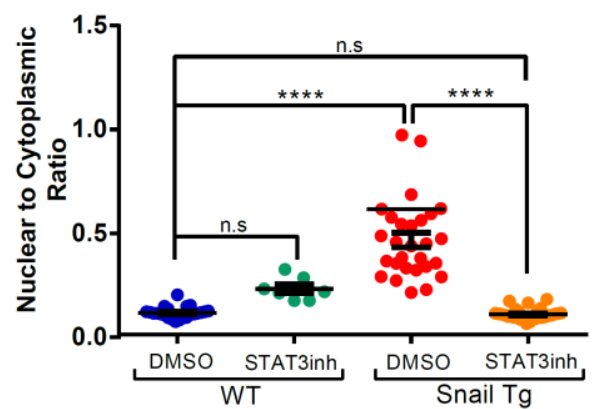

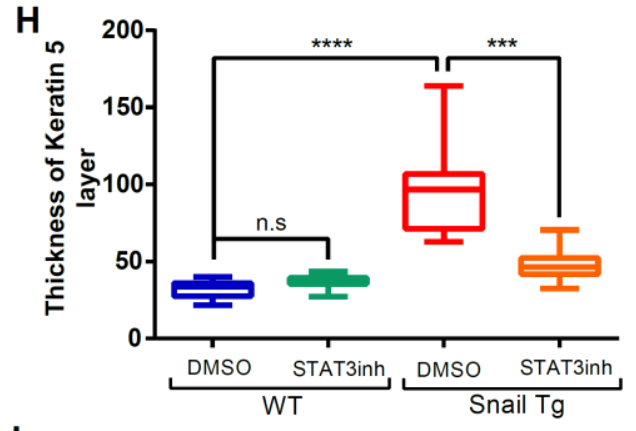

I

Figure 3. Snail mediated stem/progenitor cell maintenance is dependent upon STAT3 activation.

(A) Immunofluorescence of total STAT3 (green) and DAPI (blue) on WT and Snail Tg keratinocytes. Scale bar $=10 \mu \mathrm{m}$.

(B) Western blot for phosphorylated STAT3 (pSTAT3) and total STAT3 in WT and Snail Tg keratinocytes.

GAPDH was used as loading control.

(C) Average number of colonies formed by WT and Snail Tg keratinocytes in the presence or absence of STAT3 inhibitor or vehicle control, DMSO. $\mathrm{n}=3$ for each seeding.

(D) qPCR analysis of stem cell gene expression in WT and Snail Tg keratinocytes upon STAT3 inhibition $(n=3)$.

(E) Nuclear to cytoplasmic ratio of WT and Snail Tg keratinocytes upon STAT3 inhibition.

(F) Immunofluorescence of stem cell marker CD44 in green in WT, Snail Tg, and Snail Tg+STAT3inh cells. Scale bar: $2 \mu m$.

(G) Immunofluorescence panels showing stem/progenitor layer of the epidermis marked by keratin 5 in red on WT and Snail Tg skin upon STAT3 inhibition. Dotted line represents the basement membrane, which separates the epidermis (epi) from the underlying dermis (der). Insets in each panel are magnified views of the boxed areas of the epidermis. Scale bar: $50 \mu m$

(H) Quantification of thickness of the stem/progenitor layer in the WT and Snail Tg skin post STAT3 inhibition, $n=2$ animals each.

(I) Quantification of the number of p63 positive cells in the suprabasal layer of the WT and Snail Tg epidermis after STAT3 inhibition.

Error bars depict \pm SEM. ${ }^{* *} \mathrm{P}<0.01,{ }^{* * *} \mathrm{P}<0.001,{ }^{* \star * *} \mathrm{P}<0.0001$ and $\mathrm{n} . \mathrm{s}=$ not significant. See also Figure S3. 
bioRxiv preprint doi: https:/doi.org/10.1101/2021.06.26.450022; this version posted June 29, 2021. The copyright holder for this preprint (which was not certified by peer review) is the author/funder, who has granted bioRxiv a license to display the preprint in perpetuity. It is made available under aCC-BY-NC-ND 4.0 International license.

\section{Mindin secreted by Snail Tg keratinocytes activates STAT3 in an autocrine fashion}

We further sought to elucidate the molecular pathway linking Snail with STAT3 activation. STAT3 activation is regulated via receptor tyrosine kinases (Grandis et al., 1998) or by nonreceptor tyrosine kinases (Bowman et al., 2000), which are stimulated by multiple extracellular ligands (Rébé et al., 2013). We therefore postulated that keratinocytes expressing Snail secrete proteins to the extracellular milieu capable of activating STAT3. To test this hypothesis, we treated primary keratinocytes with conditioned media obtained from cultured WT or Snail Tg keratinocytes and assessed the levels of STAT3 phosphorylation. Snail Tg conditioned media increased the levels of activated STAT3 compared to wild type conditioned media (Figure 4A and S4A). We next embarked upon identifying the specific component/s in the Snail Tg conditioned media that is responsible for this effect.

Interestingly, we observed increased levels of secreted Mindin in non-permeabilized Snail Tg skin compared to WT tissue (Figure S4B). Likewise, Mindin RNA is upregulated in the Snail Tg keratinocytes compared to the WT cells (Figure 4B). Mindin has attracted recent attention due to its upregulation in numerous carcinomas (Jin et al., 2017; Lucarelli et al., 2013a; Ni et al., 2019; Simon et al., 2007; Zhang et al., 2015) which underlies its use as a diagnostic biomarker. Consistent with a role in mediating keratinocyte stemness, the epidermal hyperplasia found in the Snail Tg skin is reduced to almost WT levels when Mindin was genetically ablated (Figure 4C and Figure S4C). Moreover, we observed that the expansion of the stem/progenitor population in the epidermis of Snail Tg skin, is reduced in the absence of Mindin (Figure 4C). Further, we examined if Mindin is the link between Snail and STAT3 activation. In Snail Tg/Mindin KO skin, there was a significant reduction in the levels of activated STAT3 compared to the Snail Tg skin (Figure 4C). Concomitant with the in vivo observations, Snail Tg keratinocytes lacking Mindin showed reduced self-renewal capacity (Figure 4D), decreased expression of stem cell genes (Figure 4E), and a lower nuclear to cytoplasmic ratio (Figure 4F). Moreover, the level of activated STAT3 in the Snail Tg/Mindin KO keratinocytes was lower compared to Snail Tg cells (Figure S4D).

To test the sufficiency of Mindin to activate STAT3, we treated WT keratinocytes with recombinant Mindin and analysed the levels of phosphorylated protein. We observed that Mindin treatment resulted in elevated levels of activated STAT3 (Figure 4G, Figure S4E-F). We further investigated if Mindin is itself sufficient to enhance the stem/progenitor characteristics. Mindin treated keratinocytes exhibited an increased colony forming capacity (Figure S4G), a higher NCR (Figure S3H), and elevated expression of stem cell markers (Figure S4I-J) in a STAT3-dependent manner. In summary, Mindin is sufficient to endow epidermal keratinocytes with stem/progenitor characteristics through the activation of STAT3 (Figure 4H). 
bioRxiv preprint doi: https://doi.org/10.1101/2021.06.26.450022; this version posted June 29, 2021. The copyright holder for this preprint (which was not certified by peer review) is the author/funder, who has granted bioRxiv a license to display the preprint in perpetuity. It is made available under aCC-BY-NC-ND 4.0 International license.

A
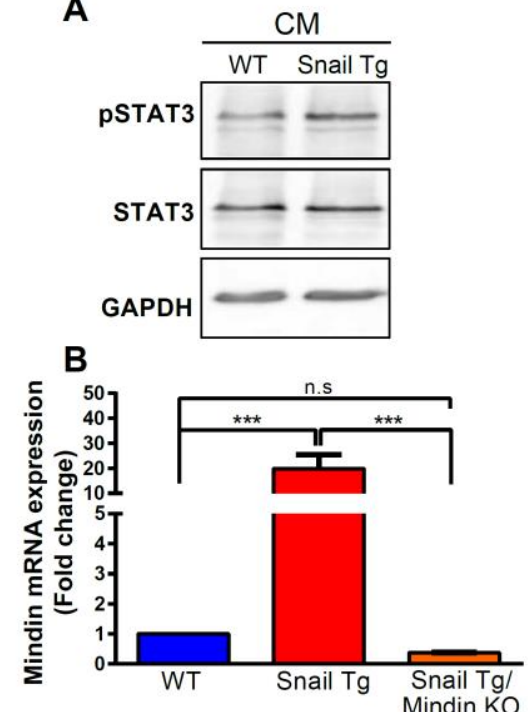

D

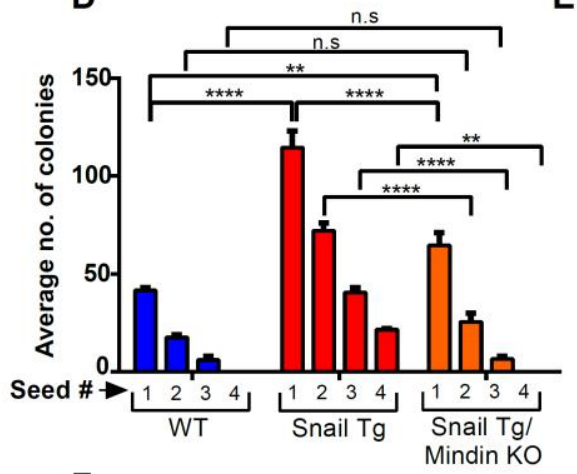

$\mathbf{F}$

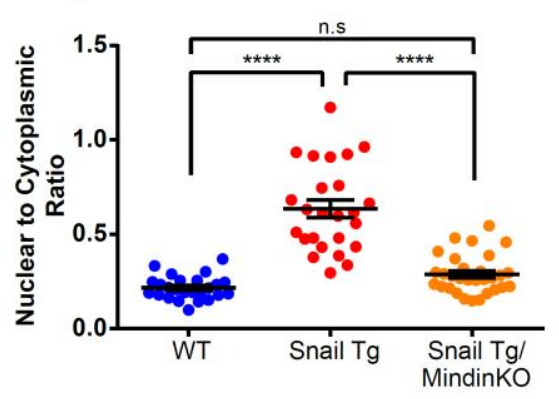

E
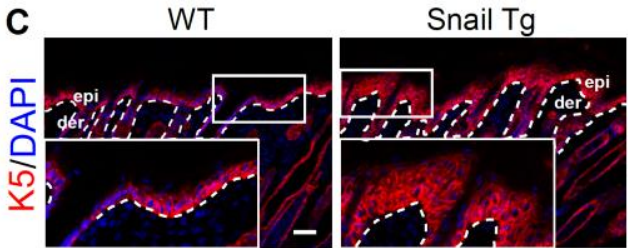

Snail Tg/Mindin KO
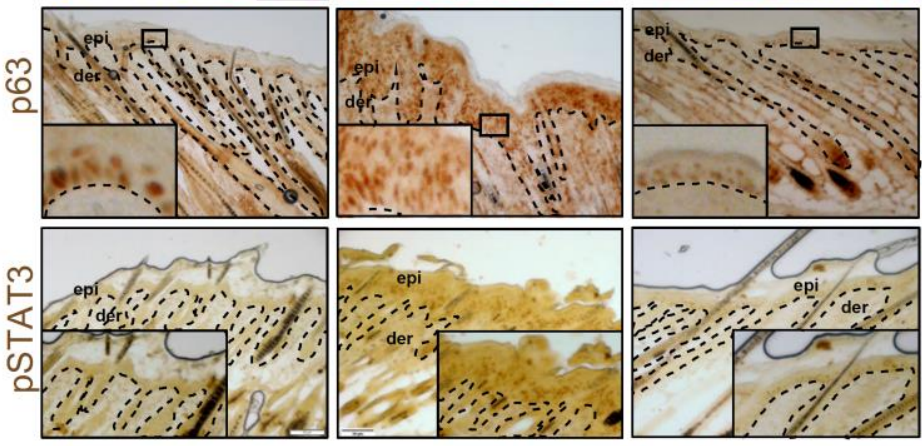

G
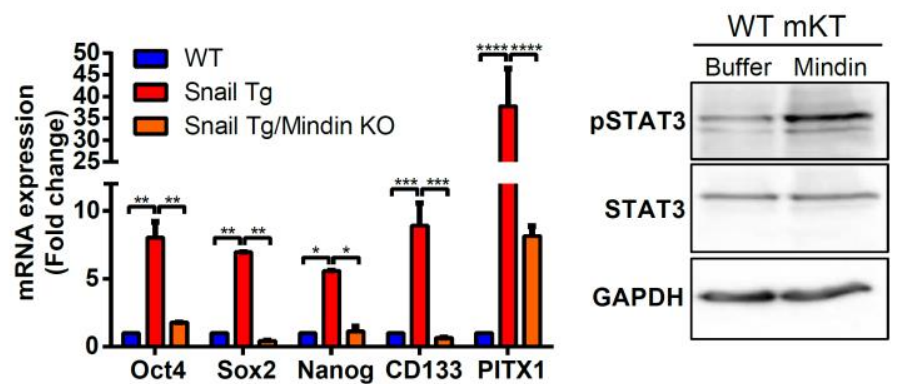

H

\begin{tabular}{|c|c|c|c|}
\hline $\begin{array}{c}\text { Properties of } \\
\text { Stem/progenitor } \\
\text { cells }\end{array}$ & $\begin{array}{c}\text { Snail } \\
\mathrm{Tg}\end{array}$ & $\begin{array}{c}\text { WT } \\
\text { +Mindn }\end{array}$ & $\begin{array}{c}\text { WT+Mindin } \\
\text { +STAT3inh }\end{array}$ \\
\hline $\begin{array}{c}\text { Colony formation } \\
\text { assay }\end{array}$ & Up & Up & Down \\
\hline $\begin{array}{c}\text { Expression of } \\
\text { stem cell genes }\end{array}$ & Up & Up & Down \\
\hline $\begin{array}{c}\text { Nuclear to } \\
\text { cytoplasmic ratio }\end{array}$ & Up & Up & Down \\
\hline $\begin{array}{c}\text { Expression of cell } \\
\text { surface marker, } \\
\text { CD44 }\end{array}$ & Up & Up & Down \\
\hline
\end{tabular}

Figure 4. Secreted Mindin by Snail Tg keratinocytes activates STAT3 in an autocrine fashion.

(A) Western blot for pSTAT3 and total STAT3 in WT cells treated with WT and Snail Tg epidermal keratinocyte conditioned media (CM). GAPDH was used as loading control $(n=3)$.

(B) qPCR analysis showing the Mindin mRNA levels in WT, Snail Tg, and Snail Tg/Mindin KO epidermal keratinocytes ( $\mathrm{n}=3$ ) (C)Top row: Immunofluorescence of keratin 5 (K5) in red to mark the stem/progenitor layer of the epidermis in WT, Snail Tg, and Snail Tg/Mindin KO skin. Scale bar: $30 \mu \mathrm{m}$. Middle row: Immunohistochemistry of keratinocyte stem cell marker, p63 in brown on WT, Snail Tg, and Snail Tg/Mindin KO skin. Bottom row: Immunohistochemistry of pSTAT3 in brown on WT, Snail Tg and Snail Tg/Mindin KO skin. Dotted line represents the basement membrane, which separates the epidermis (epi) from the underlying dermis (der). Scale bar: $50 \mu \mathrm{m}$.

(D) Average number of colonies formed by WT, Snail Tg, and Snail Tg/Mindin KO keratinocytes $(n=3)$.

(E) mRNA expression of stem cell genes Oct4, Sox2, Nanog, CD133, and PITX1 in wild type Snail Tg and Snail Tg/Mindin KO keratinocytes $(n=3)$.

(F) Quantification of the nuclear to cytoplasmic ratio of WT, Snail Tg, and Snail Tg/Mindin KO keratinocytes.

(G) Western blot for pSTAT3 and total STAT3 in WT keratinocytes treated with recombinant Mindin and buffer as control. GAPDH was used as loading control $(n=3)$.

$(\mathrm{H})$ Table summarizing the stem/progenitor properties displayed by WT, Snail Tg, WT+ Mindin, and WT+Mindin+STAT3inh keratinocytes. 'Up' depicts an increase compared to WT and 'Down' depicts a decrease compared to Snail Tg keratinocytes. Error bars depict \pm SEM. ${ }^{*} \mathrm{P}<0.05,{ }^{* *} \mathrm{P}<0.01,{ }^{* * *} \mathrm{P}<0.001,{ }^{* * * *} \mathrm{P}<0.0001$ and $\mathrm{n} . \mathrm{s}=$ not significant. See also Figure S4 
bioRxiv preprint doi: https:/doi.org/10.1101/2021.06.26.450022; this version posted June 29,2021 . The copyright holder for this preprint (which was not certified by peer review) is the author/funder, who has granted bioRxiv a license to display the preprint in perpetuity. It is made available under aCC-BY-NC-ND 4.0 International license.

\section{Src Family of Kinases mediates Mindin dependent activation of STAT3}

We then investigated the kinase responsible for phosphorylating STAT3 downstream of Mindin signalling. Mindin is reported to be ligand for integrins on immune cells which in turn activates STAT3 via Src Family of Kinases (SFKs) (Jia et al., 2005a; Xue et al., 2010). To test whether this same pathway is active in epidermal keratinocytes, we assessed the levels of activated (phosphorylated) Src in Snail Tg vs. WT keratinocytes with a phospho-pan Src antibody (Figure 5A and Figure S5A). Snail Tg keratinocytes exhibited a two-fold increase in activated Src compared to its WT counterpart. To examine whether Mindin was sufficient to activate $\mathrm{Src}$, we treated WT keratinocytes with recombinant protein. Mindin treated cells exhibited a three-fold increase in Src activation (Figure 5B and Figure S5B).

A broad-spectrum pharmacological inhibitor of SFKs led to a reduction in phosphorylated STAT3 levels in Snail Tg keratinocytes (Figure S5C). We then explored which specific SFK member(s) is responsible for Mindin mediated STAT3 activation using a knockdown approach. shRNA mediated knockdown was performed for each of the three ubiquitously expressed SFK members (c-Src, Fyn and Yes) in Snail Tg keratinocytes (Figure S5D). Knocking down either Fyn or $c$-Src resulted in a significant reduction in the levels of phosphorylated STAT3 (Figure 5C and Figure S5E). Furthermore, to functionally examine the effect of these knockdowns, we assessed their impact on the colony forming capacity of Snail Tg cells. Reduced levels of either Fyn or c-Src resulted in fewer colonies, while the Yes knockdown showed a mild effect (Figure 5D). Interestingly cells with lower levels of Fyn or Yes exhibited a reduced expression of stem cell genes (Figure 5E). Finally, we characterised SFK on the morphological parameters of keratinocyte stemness and found that Fyn and $c$-Src knock down caused a decrease in the nuclear to cytoplasmic ratio while the Yes knock down had no effect (Figure 5F and Figure S5F). Overall, these results suggest that Mindin-STAT3 mediated stem/progenitor properties is via activation of Src kinases. Notably, Fyn appears to have the broadest effect on the stem cell characteristics we analysed (Figure S5G). 
bioRxiv preprint doi: https://doi.org/10.1101/2021.06.26.450022; this version posted June 29, 2021. The copyright holder for this preprint (which was not certified by peer review) is the author/funder, who has granted bioRxiv a license to display the preprint in perpetuity. It is made available under aCC-BY-NC-ND 4.0 International license.

A

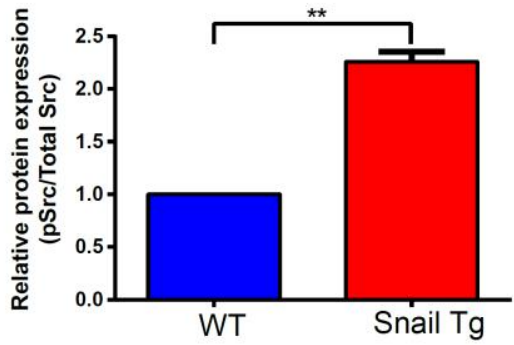

C

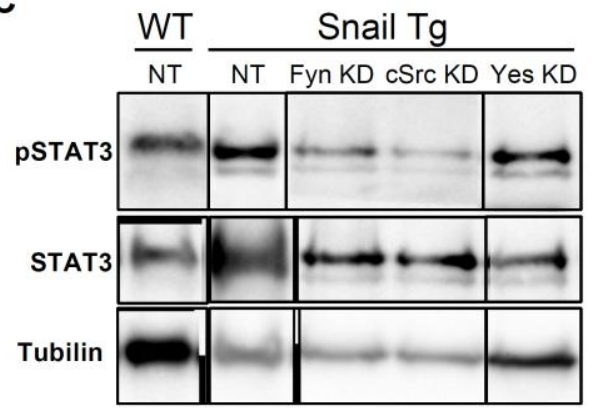

E

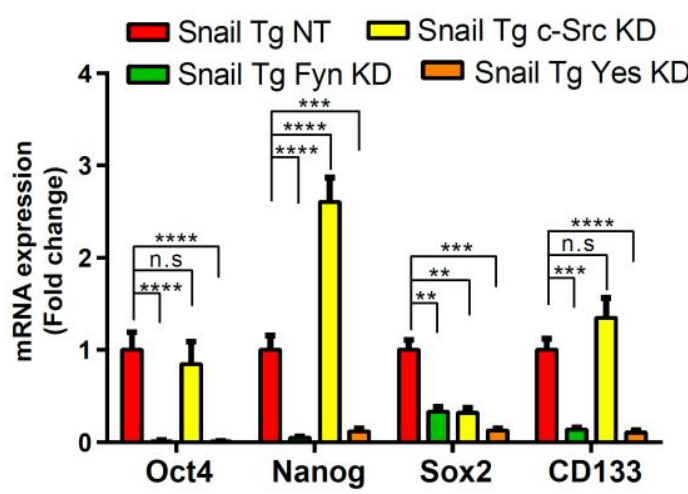

B

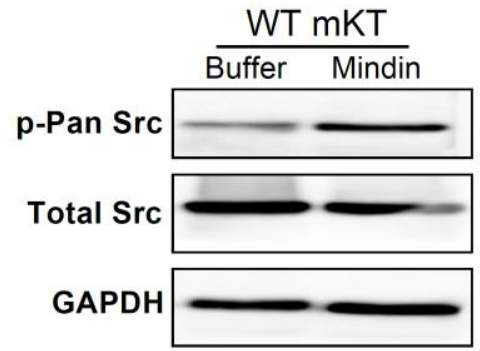

D

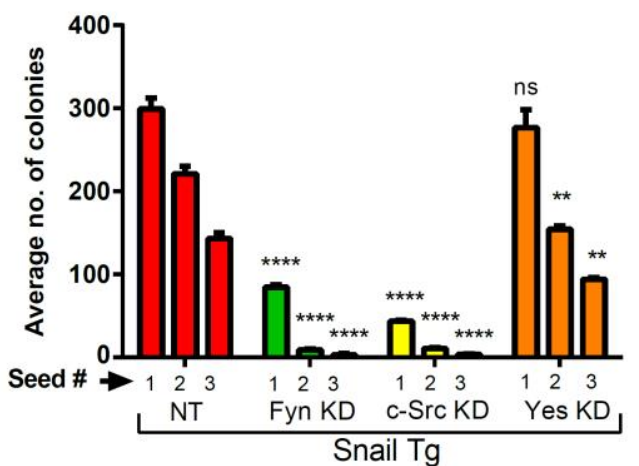

$\mathbf{F}$

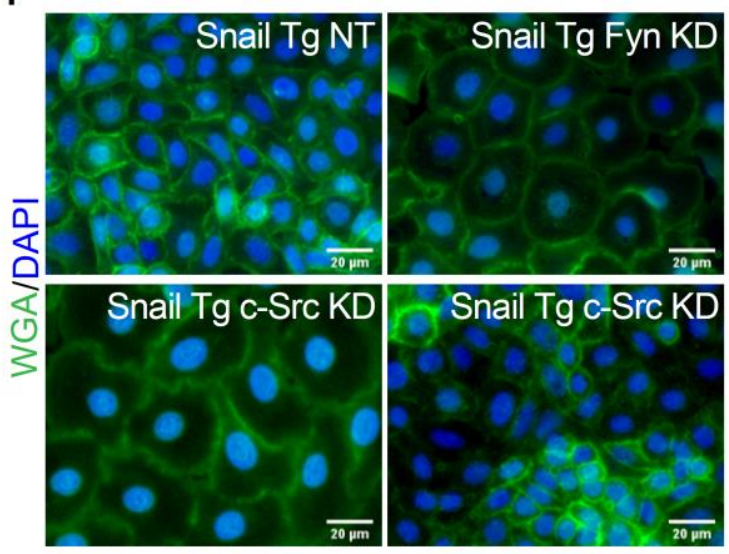

Figure 5. Src Family of Kinases mediate the Mindin dependent activation of STAT3.

(A) Quantification of western blot analysis of phospho pan Src to total Src in WT and Snail Tg keratinocytes ( $n=3$ ).

(B) Western blot for phospho pan Src and total Src in WT keratinocytes treated with Mindin protein and its buffer control.

GAPDH was used as the loading control $(n=3)$.

(C) Western blot for pSTAT3 and total STAT3 in WT and Snail Tg keratinocytes with non-targeting (NT) control and Snail Tg keratinocytes knocked down (KD) individually for Fyn, c-Src and Yes. Gamma tubulin was used as the loading control.

(D) Average number of colonies formed by Snail Tg keratinocytes knocked down for Fyn, c-Src and Yes with NT as control ( $n=3$ ).

(E) mRNA expression of stem cell genes in the Snail Tg keratinocytes individually knocked down for Fyn, c-Src and Yes with NT

as control $(n=3)$.

(F) Immunofluorescence of WGA in green marks the plasma membrane and DAPI in blue marks the nucleus. Nuclear to cytoplasmic ratio has reduced in Snail Tg cells with Fyn and c-Src KD compared to the Snail Tg NT and Yes KD cells. Scale bar: $20 \mu \mathrm{m}$.

Error bars depict \pm SEM. ${ }^{*} \mathrm{P}<0.05,{ }^{* \star} \mathrm{P}<0.01,{ }^{* \star *} \mathrm{P}<0.001,{ }^{\star \star * *} \mathrm{P}<0.0001$ and $\mathrm{n} . \mathrm{s}=$ not significant. See also Figure S5. 
bioRxiv preprint doi: https:/doi.org/10.1101/2021.06.26.450022; this version posted June 29, 2021. The copyright holder for this preprint (which was not certified by peer review) is the author/funder, who has granted bioRxiv a license to display the preprint in perpetuity. It is made available under aCC-BY-NC-ND 4.0 International license.

\section{Mindin is required for the maintenance of stem/progenitor characteristics in human cutaneous squamous cell carcinoma}

Although Mindin has been proposed to be a biomarker for certain cancers such as ovarian (Simon et al., 2007), prostate (Lucarelli et al., 2013b), and lung adenocarcinoma (Yuan et al., 2017), the precise role of Mindin in skin cancers remains elusive. Therefore, we sought to determine if Mindin mediated stemness observed in Snail Tg mouse keratinocytes is operational in human skin cancers. We first inspected the expression pattern of Mindin in various cancers and found it to be upregulated in 12 out of the 18 different cancers that were analysed (Figure S6A). In addition, a cell line (A388) derived from a patient with cutaneous squamous cell carcinoma (cSCC) (Conway et al., 1992) that expresses higher levels of Snail (Figure S6B), also exhibited higher levels of Mindin mRNA (Figure 6A). We proceeded to investigate whether the increase in Mindin levels observed in the cSCC cell has a functional role in maintaining stem/progenitor characteristics. We utilized the CRISPR/Cas9 system to knockdown Mindin in cSCC cells (cSCC-KD). cSCC cells that were selected for Mindin KD with puromycin contained a $50 \%$ reduction in the mRNA levels of Mindin compared to control cells (Figure S6C). cSCC-KD cells displayed a reduction in the expression levels of stem cell genes (Figure 6B), self-renewal capacity (Figure 6C) and nuclear to cytoplasmic ratio (Figure $6 \mathrm{D})$. Moreover, the trend observed in all these properties could be rescued upon treatment of cSCC-KD cells with recombinant Mindin, suggesting that the phenomenon is not an offtarget effect of gene editing. Furthermore, we investigated whether the Mindin mediated SrcSTAT3 signalling module is active in human CSCC cells. CSCC-KD cells exhibited reduced p-STAT3 (Figure 6E) and p-Src (Figure 6F) levels compared to its control (Figure 6E). Moreover, the reduction in SFK and STAT3 activation in cSCC-KD cells was reversed upon the treatment with recombinant Mindin. Supporting these results, the stem cell markers associated with the cSCC cells also decreased in the KD cells (Figure 6G-H).

In xenograft assays, cSCCs formed tumors in 5/5 mice while the cSCC-KD cells formed tumors in 7/10 mice. However, the size of the tumors that formed with the cSCC-KD cells were substantially smaller compared to its parental cSCC cells (Figure 6I). In addition to their size difference, the tumors formed by the CSCC-KD cells unexpectedly appeared to have less vascularization compared to that of the tumors from cSCC cells (Figure 6I). Overall, these results signify that Mindin is a critical player required for the maintenance of stem/progenitor characteristics in human squamous cell carcinoma of skin. In addition, the signalling pathway that Mindin mediates to maintain stem/progenitor characteristics in mouse is conserved in human skin cancer cells. 
A

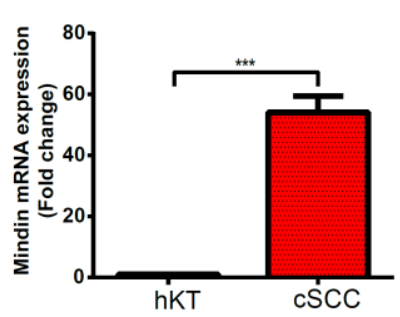

D

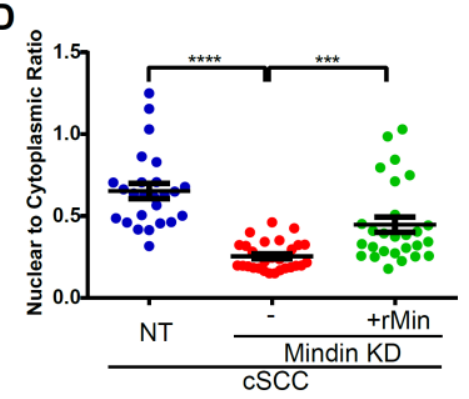

H

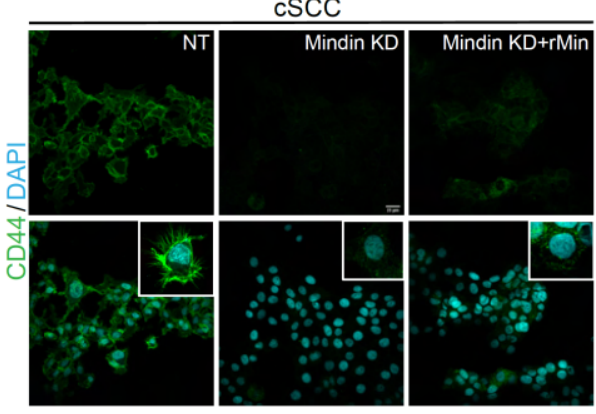

E
B $\quad 0$ CSCC NT

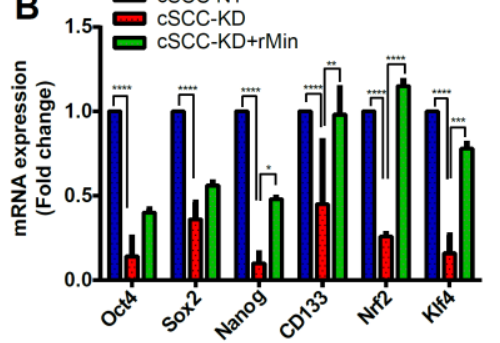

C
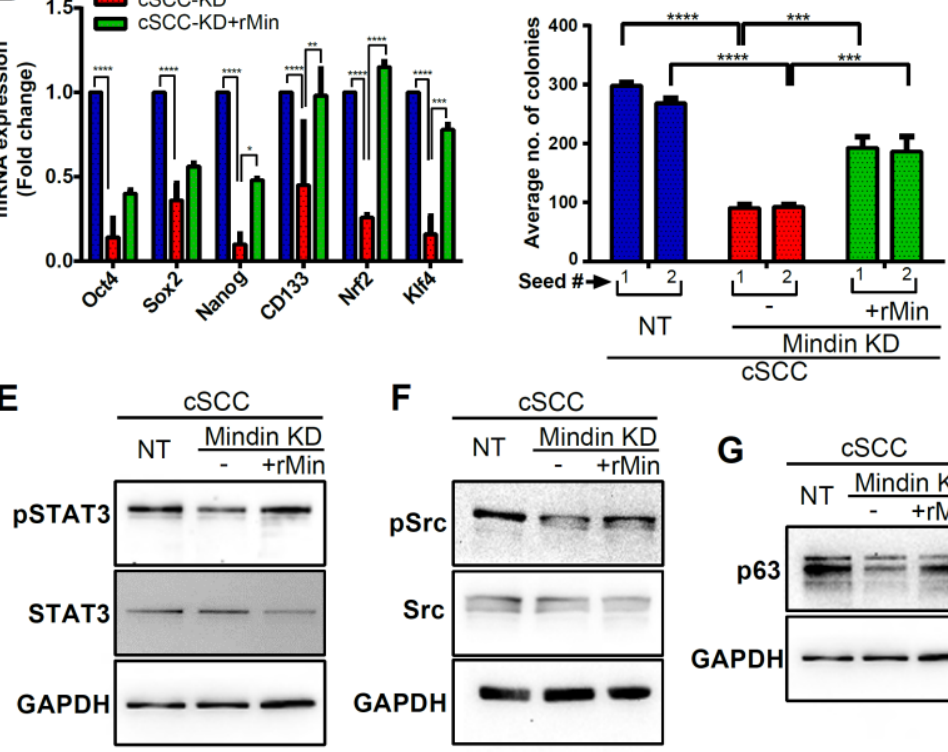

$\mathbf{F}$

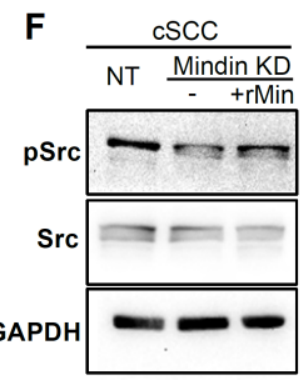

G

$\frac{\mathrm{cSCC}}{\mathrm{NT} \frac{\mathrm{Mindin} \mathrm{KD}}{+\mathrm{Min}}}$

p63

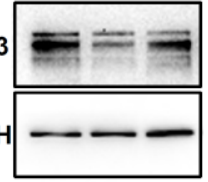

I
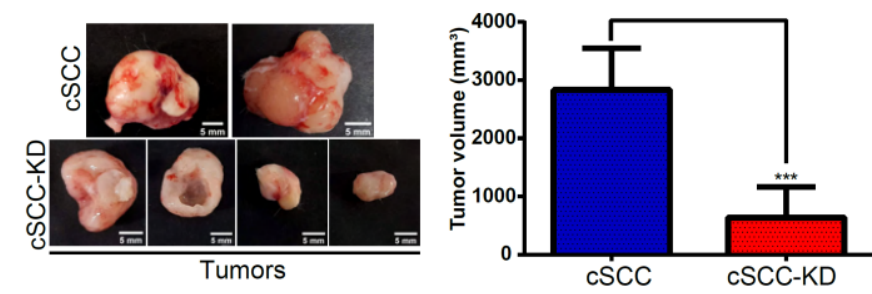

Figure 6. Mindin is required for the maintenance of stem/progenitor characteristics in cutaneous squamous cell carcinoma cells.

(A) qPCR for Mindin mRNA in patient derived cutaneous squamous cell carcinoma (cSCC) cell line compared to normal human keratinocytes $(n=3)$.

(B) mRNA expression of stem cell genes in cSCC no target (NT) control, cSCC Mindin KD (cSCC-KD) and cSCC-KD treated with recombinant Mindin $(n=3)$.

(C) Average number of colonies formed by cSCC NT control cells, CSCC-KD and CSCC-KD cells treated with recombinant Mindin ( $n=3)$.

(D) Quantification of nuclear to cytoplasmic ratio of cSCC NT control cells, CSCC-KD and cSCC-KD cells treated with recombinant Mindin.

(E-G) Western blot analysis for pSTAT3 and total STAT3 (E), pSrc and total Src (F) and p63(G) in cSCC NT control cells,

CSCC-KD and CSCC-KD cells treated with recombinant Mindin.

(H) Immunofluorescence of cell surface marker CD44 in green on cSCC NT control cells, cSCC-KD and cSCC-KD cells treated with recombinant Mindin. Scale bar: $25 \mu \mathrm{m}$

(I) Tumors formed by the cSCC cells (top) and by cSCC-KD cells (bottom) in the xenograft assay. Scale bar: $5 \mathrm{~mm}$. In the right panel is the tumor volume in $\mathrm{mm}^{3}$ of CSCC and CSCC-KD tumors.

Error bars depict \pm SEM. ${ }^{*} \mathrm{P}<0.05,{ }^{* *} \mathrm{P}<0.01,{ }^{* \star *} \mathrm{P}<0.001$, ${ }^{* * *} \mathrm{P}<0.0001$, See also Figure $\mathrm{S} 6$.

\section{Discussion}

The predominant model of Snail's contribution towards tumorigenesis in various carcinomas, invokes its canonical function in promoting an EMT (Fan et al., 2012b; Goossens et al., 2017; Smith et al., 2014; Yang et al., 2017; Zhu et al., 2012). Several studies have established Snail-mediated EMT in either transformed cell lines or cancerous cells that contain multiple genetic aberrations. Surprisingly, we observed that ectopically expressed Snail in primary epidermal keratinocytes, results in the downregulation of $E$ cadherin RNA 
bioRxiv preprint doi: https:/doi.org/10.1101/2021.06.26.450022; this version posted June 29, 2021. The copyright holder for this preprint (which was not certified by peer review) is the author/funder, who has granted bioRxiv a license to display the preprint in perpetuity. It is made available under aCC-BY-NC-ND 4.0 International license.

but not protein(Jamora et al., 2005). The notion of an EMT itself has undergone a renaissance due to the new appreciation of the spectrum of EMT characteristics (GrosseWilde et al., 2015; Pastushenko and Blanpain, 2019). Thus the EMT program is no longer considered a binary process with a completely epithelial $(E)$ or mesenchymal $(M)$ phenotype (Grosse-Wilde et al., 2015; Kröger et al., 2019). Instead, an important intermediate called the EM hybrid state, correlates with maximum stem cell characteristics (Bierie et al., 2017). However, computation of the EMT score using the transcriptome profile we generated with transgenic cells revealed a negative score $(<0)$ in both wild type and Snail Tg primary mouse keratinocytes signifying their epithelial nature (Tan et al., 2014). This also suggests that Snail is not sufficient to induce EMT in primary cells and requires an additional drive to enter the EMT program that are present in transformed and cancer cell lines.

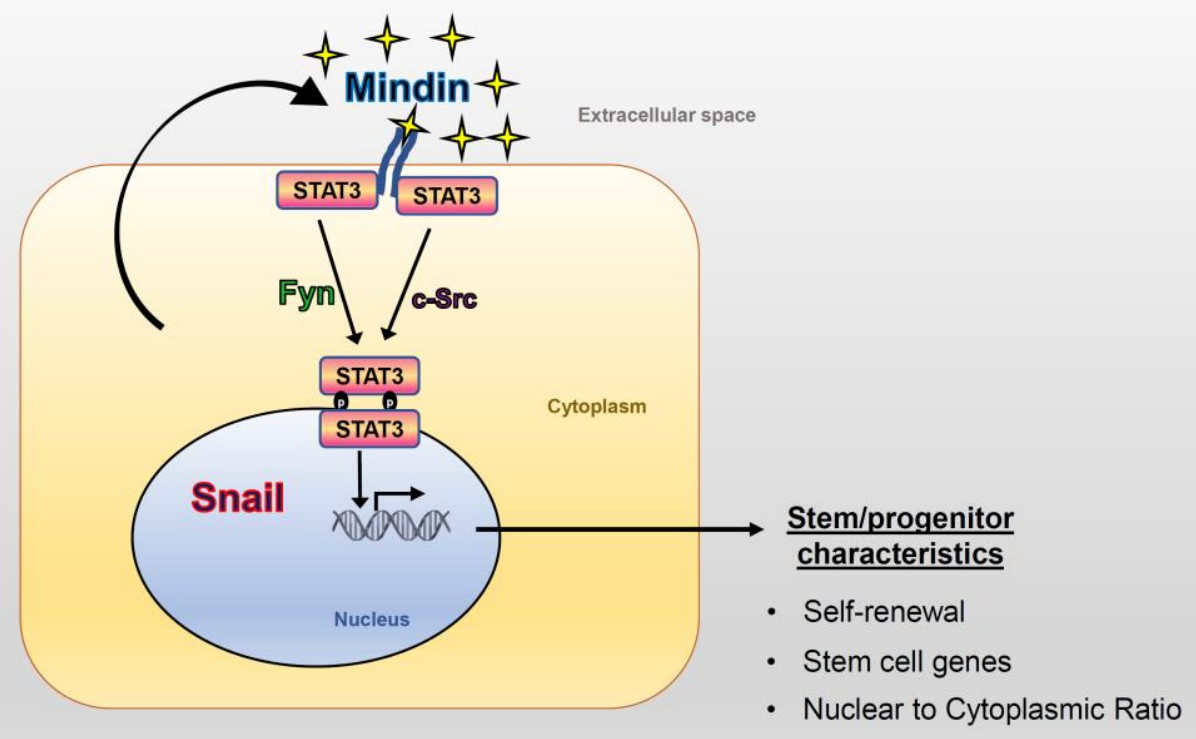

Figure 7. Model indicates that Snail expressing keratinocytes secrete Mindin to the extracellular milieu which in an autocrine fashion activates SFK-STAT3 signalling to promote stemness.

These results are consistent with studies that have implicated an EMT independent role for Snail in conferring cancer cells with stem cell like traits (De Craene et al., 2014; Goossens et al., 2017; Ma et al., 2017; Mani et al., 2009; Zhou et al., 2014). Although this association is well-recognized, the mechanistic basis underlying this connection has thus far remained elusive. Our findings indicate that Snail expressing keratinocytes utilize Mindin in an autocrine fashion to activate SFK-STAT3 signalling to promote stemness (Figure 7). This study illustrates how carcinomas are a product of factors operating at multiple cellular levels ranging from transcription factors such as Snail, to cytoplasmic proteins (i.e., SFK-STAT3), and extracellular component such as Mindin. Previously, we reported that one mechanism for STAT3 activation in epidermal keratinocytes of the Snail transgenic skin is the paracrine signaling of IL-17 released by activated resident $ү \delta T$-cells (Du et al., 2010). Interestingly, we find that the increase in the number of active yסT-cells in the Snail Tg background is substantially reduced in the absence of Mindin (Figure S7A). This is in line with previous reports demonstrating the role of this protein in recruitment and activation of other immune cells (Jia et al., 2005b). Together, these results suggest that Mindin regulates stemness in a 
multitiered fashion: it establishes an inflammatory microenvironment that reinforces the intracellular signalling pathway that resists pro-differentiation signals. In addition, the defect in keratinocyte differentiation of Tg cells (Figure 1D and F) may be facilitated by epigenetic modifications since Snail has been previously reported to associate with the PRC2 complex to inhibit epithelial differentiation (Plikus et al., 2015).

Since we have demonstrated that secreted Mindin is both necessary and sufficient to maintain stemness, one would predict that many cells within its field would be stimulated to manifest stem cell characteristics. Why, then, are the number of cancer stem cells within a tumor so few? There are overlapping possibilities that can account for this apparent contradiction: 1. Only a few cells in the tumor express Snail, so the number of cells secreting Mindin is limited and correlates with the number of cancer stem cells. Interestingly, in aggressive tumors, Snail and Mindin expression is increased along with the number of cancer stem cells (Hojo et al., 2018b; Kang et al., 2020; Zhao et al., 2020); 2. The ECM binding nature of Mindin substantially restricts its diffusion and thus limits the number of cells that is exposed to this matricellular protein; 3 . Differential expression of its cognate receptor may limit the number of responding cells. Though the receptor for Mindin on epithelial cells is unknown, it is reported that Mindin is a ligand for integrin $\alpha_{M} \beta_{2}$ and $\alpha_{4} \beta_{1}$ on macrophages and neutrophils, respectively (Jia et al., 2005a; Xue et al., 2010). It is noteworthy that these integrins also activate SFK and STAT3 containing signalling pathways (Meng and Lowell, 1998). Moreover, these two integrin pairs are reported to be upregulated in cancers and positively correlate with metastasis and progression (Alday-Parejo et al., 2019; Ganguly et al., 2013; Wu et al., 2021). Identification of the receptor of Mindin on epithelial cells can facilitate expression studies on the heterogenous population of cells within the tumor. This differential expression might explain why only a few cells within a tumor are cancer stem cells.

A notable observation made during the course of this study is that Snail expressing keratinocytes exhibit an increase in both activated STAT3 as well as total STAT3 (Figure S3B). The reason for the latter could be a direct binding of Snail on the STAT3 promoter, which has the canonical E-box sequence for Snail binding (Figure S7B). This would argue that even though Snail is classically considered a transcriptional repressor, it also has the ability to function as a transcriptional activator. This is supported by reports that Snail can transcriptionally upregulate p15INK4b (Hu et al., 2010), MMP15 (Tao et al., 2011) and Snail2 (Daisuke et al., 2006). This also explains why treatment of keratinocytes with Mindin only results in the upregulation of activated STAT3 without affecting the total amount of this protein (Figure 4G).

Given its role in maintaining stemness, STAT3 has been a focus in cancer therapy and multiple drugs targeting this protein/pathway are currently in clinical trials. However, only a few STAT3 inhibitors are approved by the FDA (Beebe et al., 2018; Zou et al., 2020). One major limitation of targeting STAT3 is that since normal cells require this signalling protein for basic cellular physiology, inhibiting this protein would have many unintended side effects. Therefore, it becomes important to target specific upstream regulators of STAT3 that would allow other physiologically important STAT3 containing signalling pathways to remain operational. In this case, Mindin would be an attractive target as Mindin KO mice are viable and fertile and Mindin activates STAT3 in cancer cells. Additionally, in the Mindin KO mice, other physiological pathways utilizing STAT3 will still be intact. For instance, the Snail Tg/ Mindin KO retains STAT3 activation in the basal keratinocytes of the epidermis where it is 
known to contribute to the proliferative potential of these cells (Figure 4). Finally, the activity of Mindin in both mouse and human squamous cell carcinoma of the skin suggests that this is a conserved process that would be an effective target for therapeutic intervention.

\section{Materials and Methods}

\section{Animal studies}

C57BI6 and NSG mice were obtained from The Jackson Laboratory (Bar Harbor, Maine) and Mindin KO mice was from You-Wen He (Department of Immunology, Duke University Medical University Medical Center) The K14-Snail Tg mouse was developed as described earlier (Jamora et al., 2005) . The K14-Snail Tg/Mindin KO mouse was generated by breeding the Mindin KO and K14-Snail Tg mice. All mice were maintained and bred the BLiSC Animal Care and Resource Centre under specific pathogen-free conditions. Mice were sacrificed between P7 and P9 (neonatal) and skin samples were collected for RNA, protein and OCT or paraffin embedding as required. All animal work was approved by the Institutional Animal Ethics Committee in the CJ lab (INS-IAE-2019/06[R1]) and SK lab (NCBS-IAC-2017/05[N]). Experiments on mice followed the norms specified by the Committee for the Purpose of Control and Supervision of Experiments on Animals (Government of India). All experimental work was approved by the Institutional Biosafety Committees of both inStem and NCBS.

\section{Gene expression}

Total RNA was isolated from skin and epidermal biopsies or keratinocytes (either proliferating or differentiated) using TRIzol Reagent or RNAiso Plus (Thermo Fisher Scientific, Takara). 1-2ug of RNA was used to synthesise cDNA using Superscript III or PrimeScript kit (Thermo Fisher Scientific, Takara). Quantitative PCR (qPCR) was done with cDNA equivalent to approximately 100ng of RNA using the Sso Fast 2x master mix (BioRad) in a Bio-Rad CFX384 machine. Actin or GAPDH expression was used as a reference for normalization. The primer sequences used are listed in Supplementary Table 1.

\section{Transcriptome data analysis}

For studying the transcriptome, total RNA was isolated from 6 samples ( 3 each from WT and Snail Tg keratinocyte samples). The RNA sample QC, NGS library (Illumina) preparation, and sequencing steps were outsourced to a commercial facility. We had received approximately 45-55 million and 80-90 million 150bp paired end reads from WT and Snail $\mathrm{Tg}$ samples, respectively. Analysis of the data was done in-house after receiving the raw sequencing reads. For the analysis, established analysis pipeline was used to study our RNA sequencing data. The quality of the raw sequencing reads was checked through FASTQC tool [https://www.bioinformatics.babraham.ac.uk/projects/fastqc/]. The low-quality reads towards both ends were trimmed using "FASTX-TRIMMER" using the parameters as "-f 11 - I 140" [http://hannonlab.cshl.edu/fastx_toolkit/index.html]. The trimmed reads (130bp*2) were then aligned to mouse reference genome (mm10, UCSC version) using "HISAT2" (Kim et al., 2019). The "SAM" outputs were converted to "BAM" files, followed by sorting using "Samtools". Respective "BAM" files were used to generate "Count" matrix using 
"HTSeq-count" (Anders et al., 2015). The count matrix was used to calculate differentially expressed genes using "DESeq2" R package (Love et al., 2014). We found 1113 genes to be significantly differentially expressed in pair-wise comparison (Adj $P$ values $<0.05$ ). These genes were used for Gene Ontology (GO) enrichment analysis using "DAVID”(Huang et al., 2009).

\section{Analysis of EMT score of primary keratinocytes}

EMT scores were calculated from the transcriptome data for all the samples and computed using the previously published EMT signature and the two-sample Kolmogorov-Smirnovbased method [PMID: 25214461, 28262832]. Gene expression data was mapped to the generic cell line based EMT signature genes (total =218; epithelial = 170 and mesenchymal $=48$ ) derived using gene expression profiles from tumor and cell lines from various cancers. First, the empirical cumulative distribution function (ECDF) was estimated for Epithelial and Mesenchymal gene sets. Then 2KS test was employed to compute the difference between Mesenchymal ECDF and Epithelial ECDF. The 2KS score was considered as the EMT score. A sample with a positive EMT score and significant $P$ value exhibits a more Mesenchymal phenotype, whereas a negative EMT score and significant $P$ value reflects a more Epithelial phenotype. A sample with insignificant $P$ value is considered intermediate.

\section{Western blot analysis}

The keratinocyte lysates were prepared in RIPA buffer with protease inhibitors (Sigma, \#P2714) and sonicated at $4^{\circ} \mathrm{C}$. Protein lysate was then mixed with $4 \mathrm{X}$ Laemmli sample buffer and heated at $95^{\circ} \mathrm{C}$ for 3 min before loading on the polyacrylamide gel. This was later transferred onto a nitrocellulose membrane. After the transfer, the membrane was blocked using either 5\% BSA (Bovine Serum Albumin) in Tris buffer Saline containing 0.1\% Tween (TBST) for phosphorylated proteins or $5 \%$ Blotto (Santa Cruz Biotechnology, sc-2325) for $60 \mathrm{~min}$. The blots were probed overnight with the respective primary antibody (Supplementary Table 2). After washing with TBST, the blots were probed with HRP-tagged secondary antibodies and washed again. Signals were detected using Enhanced Chemiluminescence substrate (ECL, Merck) and iBright FL (Thermo) detector. The bands were quantified using Fiji (ImageJ) software and normalized to loading controls.

\section{Immunostaining and histology}

Skin tissues were either fixed in Bouin's solution, dehydrated, and embedded in paraffin or immediately embedded in OCT (Leica). For staining the OCT sections, $10-15 \mu$ m-thick sections were fixed in 4\% paraformaldehyde (PFA) before proceeding to the primary antibody staining. Refer the Supplementary Table 2 for the list of primary antibodies used and their respective dilutions. Alexa Fluor 488- or Alexa Fluor 568-labelled secondary antibodies (Jackson ImmunoResearch) were used at a dilution of 1:300. DAPI or Hoechst stain was used to mark nucleus. For paraffin tissue staining, the sections were rehydrated followed by antigen retrieval in $10 \mathrm{mM}$ sodium citrate buffer $(\mathrm{pH} 6) .3 \% \mathrm{H}_{2} \mathrm{O}_{2}$ incubation was performed after primary antibody incubation and HRP-labelled secondary antibodies (Jackson ImmunoResearch) was used for IHC. Development was done using DAB substrate (Vector Laboratories; SK4105) to manufacturer's instructions. For secreted protein staining, 
bioRxiv preprint doi: https:/doi.org/10.1101/2021.06.26.450022; this version posted June 29, 2021. The copyright holder for this preprint

the use of detergent was completely avoided to prevent permeabilization, and K5 staining was used as an internal control. Imaging was done on an Olympus IX73 microscope or FV1000 confocal microscope and analysed on the Fiji software.

\section{Calculation of Nuclear to Cytoplasmic Ratio (NCR)}

Primary keratinocytes and A388 cells were cultured on collagen (Millipore) coated coverslips and fixed with $4 \%$ PFA. Cells were stained with Wheat Germ Agglutinin-Alexa fluor 488(WGA) (Invitrogen) without permeabilising them. After washes with 1xPBS, cells were stained with DAPI and mounted with $80 \%$ glycerol. Images of the cells were obtained on Olympus IX73 microscope. Using the Fiji software, areas of the entire cell (by marking the outline of the cell using WGA as reference) and nucleus (with DAPI as reference) were obtained. Cytoplasmic area was calculated by taking the difference between the cell area and nuclear area. With these measurements, the ratio of nuclear area to cytoplasmic area was calculated.

\section{Cell culture}

Primary epidermal keratinocytes were isolated and cultured as described previously in (Nowak and Fuchs, 2009). The keratinocytes were grown in low calcium (50uM) E-media for most of the assays and for the differentiation assay, E-media containing $1.2 \mathrm{mM}$ calcium was used and cultured for 48 hours. Treatment with recombinant Mindin protein and conditioned media was done for 24 hours. Human cutaneous squamous cell carcinoma cell line, A388 provided by Benjamin D. Yu (University of California, San Diego) was cultured in DMEM high glucose media with $10 \%$ FBS. All cells were processed as required for RNA and protein extraction or staining.

\section{Colony formation assay}

Self-renewal of cells was measured by colony formation assay as described in (Franken et al., 2006). Briefly, single cells of keratinocytes or CSCC were seeded at a very low-density of 1000 cells/well for each seeding in a 6-well dish and was allowed to form colonies for 7 days. Colonies were counted under a microscope and were trypsinzed for the next seeding.

\section{Xenograft Assay}

Primary keratinocytes (WT and Snail Tg) and cSCC cell lines (EGFP ctrl and Mindin KD) were cultured and $0.25 \times 10^{6}$ cells were used per injection for each graft. 1: 1 ratio of cells in media to Matrigel with reduced growth factors (Corning) was prepared on ice. 2 months old male NSG animals (The Jackson Laboratories) which were maintained and bred at the animal facility at the NCBS under specific pathogen-free conditions, were used for this assay. Cells prepared in Matrigel were injected subcutaneously in the right flank region of the mice. Animals were monitored for tumor development. 8 weeks post injection, animals were sacrificed, and the tumors were collected, and measurements were taken. Tumor volume in $\mathrm{mm}^{3}$ was calculated using the formula; Volume $=\left[\left(\right.\right.$ lengthXwidth $\left.\left.{ }^{2}\right) / 2\right]$. The tumors were subsequently dissociated into single cells using Dispase (Invitrogen) and trypsin (Sigma) and serially grafted. 


\section{shRNA mediated knock down}

All lentivirus production and transduction experiments were done in the BLiSC BSL-2 facility. HEK293T cells well cultured in a $10 \mathrm{~cm}$ dish till they were $70-80$ percent confluent. The cells were then co-transfected with three plasmids- shRNA-pZip-mEf1a $(5 \mu \mathrm{g})$, psPAX2 $(3.75 \mu \mathrm{g})$, and pMD2.g $(1.25 \mu \mathrm{g})$ (total DNA - 10 $\mathrm{g}$ ) using Lipofectamine LTX reagent (Invitrogen). For transfection, the above-mentioned amounts of DNA were suspended in 500 $\mu$ l plain DMEM to which $10 \mu$ l of plus reagent was added. Meanwhile, 30 $\mu$ l Lipofectamine LTX reagent was dissolved in 500 $\mu$ l plain DMEM in another tube. After incubating 10 min at RT, DNA suspension was added to LTX reagent suspension. The mixture was incubated for 15-20 mins. Fresh DMEM with $10 \%$ FBS $(5 \mathrm{ml})$ was added to the HEK293T cells, and the transfection mixture was added dropwise the cells with fresh medium. The media was changed 12-16 hours post transfection. The Lentivirus was cultivated $24 \mathrm{hrs}, 48 \mathrm{hrs}$ and $72 \mathrm{hrs}$ post first media change and all collections were pooled. The presence of lentivirus was tested using lenti go-stix. The virus was concentrated in a 100KDa Amicon centrifugation unit (Merck) at $5000 \mathrm{~g}$ for 15 mins to achieve a 10 -fold concentration. The concentrated lentiviral particles were then titrated and added on mouse keratinocytes for infection. $72 \mathrm{~h}$ post infection \%GFP+ cells were estimated. Titre that gave $50-60 \%$ transduction efficiency was then used for further downstream experiments. For all downstream experiments $72 \mathrm{~h}$ post infection cells were exposed to puromycin selection $(1 \mu \mathrm{g} / \mathrm{ml})$ for 4 days. shRNA constructs against mouse c-Src, Fyn and Yes was procured from Transomics in vector pZIP-mEf1a. For the sequences refer Supplementary Table 3.

\section{CRISPR/Cas9 mediated Mindin knockdown in cSCC cells}

CRISPR/Cas9 tool was used to knockdown Mindin in cSCC cells (cSCC-KD). The Lentiviral backbone transfer plasmid p-lentiCRISPR - EGFP sgRNA 1 (Addgene Cat \#51760) was used to express human codon-optimized Cas9 protein. The puromycin resistance in this plasmid utilizes EFS promoter and an EGFP targeting synthetic single-guide RNA (sgRNA) element from $U 6$ promoter. This plasmid was used as the negative control in our study. The viral packaging plasmid psPAX2 (Addgene Cat\# 12260) and viral envelope plasmid pMD2.G (Addgene Cat\# 12259) were purchased from Addgene USA.

Plasmid engineering

The EGFP sgRNA 1 sequence of p-lentiCRISPR - EGFP sgRNA 1 plasmid has been replaced by customized Mindin specific single-guide RNA (sgRNA) M226R CCGCGCATAGCTCCGACTACAGC (226 nucleotide regions of NM_012445.4:44-1039 Homo sapiens spondin 2) using Quick change mutagenesis with h-M226RgRNA RP (CGCATAGCTCCGACTACAGCGGTGTTTCGTCCTTTCCAC) and h-M226RgRNA FP (GCTGTAGTCGGAGCTATGCGGTTTTAGAGCTAGAAATAGCAAGTTAAAATAAG). The plasmid was further confirmed with sequencing. This transfer vector plasmid is named as $p-$ lentiCRISPR-M226R sgRNA.

\section{Lentivirus production and Transduction}

The Lentivirus production work was performed in BSL2 facility following the assigned guidelines. 4 million HEK293T cells were seeded to $10 \mathrm{~cm}$ dish. After a day, the cells were co-transfected with transfer plasmid $(6 \mu \mathrm{g})$, packaging plasmid psPAX2 $(3 \mu \mathrm{g})$ and envelope

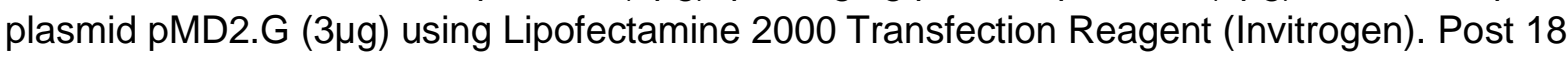


bioRxiv preprint doi: https:/doi.org/10.1101/2021.06.26.450022; this version posted June 29, 2021. The copyright holder for this preprint

$\mathrm{hr}$, transfection media was changed with fresh virus production media (DMEM+10\% FBS). After 48 and 72 hours, the $10 \mathrm{ml}$ media supernatant having lentiviral particles was collected and filtered with $0.45 \mu \mathrm{m}$ membrane. The $20 \mathrm{ml}$ media was further concentrated to 40 times (500 ul). The concentrated viral particles were frozen in 25 microliters aliquots in -80-degree deep freezers. Both M226R and negative control lentiviral particles were used further to infect the cSCC cells. The cSCC cells ( 0.3 million) were seeded into in 6 well plate. The cells were treated with various dilutions of lentiviral particles $(0,50,100,200,400$ and 500). After $24 \mathrm{hr}$ post infection the media was changed with fresh media containing puromycin $(1 \mu \mathrm{g} / \mathrm{ml})$. The appearance of resistance foci was observed in various dilutions as compared to zero dilution treatment. The $400^{\text {th }}$ dilution provided single isolated foci which were used for the experiments. The puromycin selected cells were cultured in DMEM media containing $10 \%$ FBS and cells were collected for RNA extraction and validation of the knockdown.

\section{Electron microscopy}

Skin samples from P7 WT and Snail Tg pups were fixed in 2\% glutaraldehyde, 4\% formaldehyde in $0.05 \mathrm{M}$ sodium cacodylate, and $2 \mathrm{mM}$ calcium chloride and then embedded in EPON resin and processed. Slices were imaged using the MERLIN Compact VP Scanning Electron Microscope in the BLiSC EM facility.

\section{Statistics}

Comparisons of 2 groups were done using a 1-tailed, paired Student's $t$ test or a 1-tailed Mann-Whitney $U$ test. One-way ANOVA followed by Tukey's post hoc analysis and Two-way ANOVA was used for multiple group comparisons. GraphPad Prism 6 (GraphPad Software) was used for all statistical analyses. Data represent the mean \pm SEM. $P$ values of less than 0.05 were considered significant.

\section{Acknowledgements}

The authors would like to thank Satyajit Mayor, Maneesha Inamdar, Subhasri Ghosh and members of the Jamora laboratory for their critical review of the work and insightful discussions. The authors also thank Drs. Deepak Arya, Sangeetha Raajkamal, and Yogesh Chandra, and Gaurav Kansagara for their technical assistance. This work was supported by core funds from the Institute for Stem Cell Science and Regenerative Medicine (inStem), Bellary Road, Bangalore, India and grants from the Department of Biotechnology of the Government of India (BT/PR8738/AGR/36/770/2013) and (BT/PR32539/BRB/10/1814/2019), the National Institute of Arthritis and Musculoskeletal and Skin Diseases (NIAMS), NIH (5R01AR053185-03); and the American Cancer Society (15457-RSG-08-164-01-DDC), and by a Hellman Faculty Fellowship to CJ; Work in the SK lab is supported by National Center for Biological Sciences, Tata Institute for Fundamental Research (NCBS-TIFR) planned funds. RKZ was supported by a Junior Research Fellowship from the Department of Biotechnology (DBT/JRF/13/AL/486). Animal studies were partially supported by the National Mouse Research Resource (NaMoR) grant BT/PR5981/MED/31/181/2012;2013-2016;2018 and 102/IFD/SAN/5003/2017-2018 from the Department of Biotechnology. We thank the staff of the BLiSC Animal Care and Resource Centre for assistance with animal husbandry, the BLiSC Central Imaging and Flow Cytometry Facility for help with image acquisition, and the BLiSC Electron Microscopy facility 
for ultrastructural analysis of the skin, and Dr. Benjamin D. Yu (University of California, San Diego) for the gift of the A388 cell line.

\section{Author contribution}

Conceptualization, K.B. and C.J.; Methodology, K.B. and C.J.; Investigation, K.B., B.D., S.K., R.K.Z., R.S., T.M., R.D. and A.G.; Validation, K.B., B.D. and S.K.; Formal Analysis, R.D. and J.S., P.K.; Resources, C.J., S.K, R.S., A.G., and Y.W.H., Writing - Original Draft, K.B. and C.J.; Funding Acquisition, C.J. and S.K.; Supervision, C.J. and S.K.

\section{References}

Alday-Parejo, B., Stupp, R., Rüegg, C., 2019. Are integrins still practicable targets for anticancer therapy? Cancers (Basel). https://doi.org/10.3390/cancers11070978

Anders, S., Pyl, P.T., Huber, W., 2015. HTSeq-A Python framework to work with highthroughput sequencing data. Bioinformatics 31, 166-169. https://doi.org/10.1093/bioinformatics/btu638

Beebe, J.D., Liu, J.Y., Zhang, J.T., 2018. Two decades of research in discovery of anticancer drugs targeting STAT3, how close are we? Pharmacol. Ther. https://doi.org/10.1016/j.pharmthera.2018.06.006

Bierie, B., Pierce, S.E., Kroeger, C., Stover, D.G., Pattabiraman, D.R., Thiru, P., Donaher, J.L., Reinhardt, F., Chaffer, C.L., Keckesova, Z., Weinberg, R.A., 2017. Integrin- $\beta 4$ identifies cancer stem cell-enriched populations of partially mesenchymal carcinoma cells. Proc. Natl. Acad. Sci. U. S. A. 114, E2337-E2346.

https://doi.org/10.1073/pnas.1618298114

Bikle, D.D., Xie, Z., Tu, C.L., 2012. Calcium regulation of keratinocyte differentiation. Expert Rev. Endocrinol. Metab. https://doi.org/10.1586/eem.12.34

Blanpain, C., Fuchs, E., 2007. P63: Revving up epithelial stem-cell potential. Nat. Cell Biol. 9, 731-733. https://doi.org/10.1038/ncb0707-731

Bowman, T., Garcia, R., Turkson, J., Jove, R., 2000. STATs in oncogenesis 2474-2488.

Conway, K., Morgan, D., Phillips, K.K., Yuspa, S.H., Weissman, B.E., 1992. Tumorigenic Suppression of a Human Cutaneous Squamous Cell Carcinoma Cell Line in the Nude Mouse Skin Graft Assay 1, CANCER RESEARCH.

Daisuke, S., Suzuki, T., Osumi, N., Wakamatsu, Y., 2006. Cooperative action of Sox9, Snail2 and PKA signaling in early neural crest development. Development 133, 13231333. https://doi.org/10.1242/dev.02297

De Craene, B., Denecker, G., Vermassen, P., Taminau, J., Mauch, C., Derore, A., Jonkers, J., Fuchs, E., Berx, G., 2014. Epidermal Snail expression drives skin cancer initiation and progression through enhanced cytoprotection, epidermal stem/progenitor cell expansion and enhanced metastatic potential. Cell Death Differ. 21, 310-320. https://doi.org/10.1038/cdd.2013.148

Du, F., Nakamura, Y., Tan, T.L., Lee, P., Lee, R., Yu, B., Jamora, C., 2010. Expression of snail in epidermal keratinocytes promotes cutaneous inflammation and hyperplasia 
conducive to tumor formation. Cancer Res. 70, 10080-10089.

https://doi.org/10.1158/0008-5472.CAN-10-0324

Fan, F., Samuel, S., Evans, K.W., Lu, J., Xia, L., Zhou, Y., Sceusi, E., Tozzi, F., Ye, X., Mani, S.A., Ellis, L.M., 2012a. Overexpression of Snail induces epithelial-mesenchymal transition and a cancer stem cell-like phenotype in human colorectal cancer cells. Cancer Med. 1, 5-16. https://doi.org/10.1002/cam4.4

Fan, F., Samuel, S., Evans, K.W., Lu, J., Xia, L., Zhou, Y., Sceusi, E., Tozzi, F., Ye, X.C., Mani, S.A., Ellis, L.M., 2012b. Overexpression of Snail induces epithelial-mesenchymal transition and a cancer stem cell-like phenotype in human colorectal cancer cells. Cancer Med. 1, 5-16. https://doi.org/10.1002/cam4.4

Franken, N.A.P., Rodermond, H.M., Stap, J., Haveman, J., van Bree, C., 2006. Clonogenic assay of cells in vitro. Nat. Protoc. 1, 2315-2319. https://doi.org/10.1038/nprot.2006.339

Fuchs, E., 2008. Skin stem cells: Rising to the surface. J. Cell Biol. https://doi.org/10.1083/jcb.200708185

Galoczova, M., Coates, P., Vojtesek, B., 2018. STAT3, stem cells, cancer stem cells and p63. Cell. Mol. Biol. Lett. https://doi.org/10.1186/s11658-018-0078-0

Ganguly, K.K., Pal, S., Moulik, S., Chatterjee, A., 2013. Integrins and metastasis. Cell Adhes. Migr. https://doi.org/10.4161/cam.23840

Goossens, S., Vandamme, N., Van Vlierberghe, P., Berx, G., 2017. EMT transcription factors in cancer development re-evaluated: Beyond EMT and MET. Biochim. Biophys. Acta - Rev. Cancer. https://doi.org/10.1016/j.bbcan.2017.06.006

Grandis, J.R., Pitt, A.S., Tweardy, D.J., 1998. Requirement of Stat3 but not Stat1 activation for epidermal growth factor receptor- mediated cell growth In vitro. Find the latest version : 102, 1385-1392.

Grosse-Wilde, A., Fouquier d'Hérouël, A., McIntosh, E., Ertaylan, G., Skupin, A., Kuestner, R.E., del Sol, A., Walters, K.-A., Huang, S., 2015. Stemness of the hybrid Epithelial/Mesenchymal State in Breast Cancer and Its Association with Poor Survival. PLoS One 10, e0126522. https://doi.org/10.1371/journal.pone.0126522

Guo, S., Deng, C.X., 2018. Effect of stromal cells in tumor microenvironment on metastasis initiation. Int. J. Biol. Sci. https://doi.org/10.7150/ijbs.25720

Hojo, N., Huisken, A.L., Wang, H., Chirshev, E., Kim, N.S., Nguyen, S.M., Campos, H., Glackin, C.A., loffe, Y.J., Unternaehrer, J.J., 2018a. Snail knockdown reverses stemness and inhibits tumour growth in ovarian cancer. Sci. Rep. 8, 1-10. https://doi.org/10.1038/s41598-018-27021-z

Hojo, N., Huisken, A.L., Wang, H., Chirshev, E., Kim, N.S., Nguyen, S.M., Campos, H., Glackin, C.A., loffe, Y.J., Unternaehrer, J.J., 2018b. Snail knockdown reverses stemness and inhibits tumour growth in ovarian cancer. Sci. Rep. 8, 1-10. https://doi.org/10.1038/s41598-018-27021-z

Hu, C.T., Chang, T.Y., Cheng, C.C., Liu, C.S., Wu, J.R., Li, M.C., Wu, W.S., 2010. Snail associates with EGR-1 and SP-1 to upregulate transcriptional activation of p15INK4b. FEBS J. 277, 1202-1218. https://doi.org/10.1111/j.1742-4658.2009.07553.x

Huang, D.W., Sherman, B.T., Lempicki, R.A., 2009. Systematic and integrative analysis of large gene lists using DAVID bioinformatics resources. Nat. Protoc. 4, 44-57.

https://doi.org/10.1038/nprot.2008.211 
Jamora, C., Lee, P., Kocieniewski, P., Azhar, M., Hosokawa, R., Chai, Y., Fuchs, E., 2005. A signaling pathway involving TGF- $\beta 2$ and snail in hair follicle morphogenesis. PLoS Biol. 3. https://doi.org/10.1371/journal.pbio.0030011

Jia, W., Li, H., He, Y.W., 2005a. The extracellular matrix protein mindin serves as an integrin ligand and is critical for inflammatory cell recruitment. Blood 106, 3854-3859. https://doi.org/10.1182/blood-2005-04-1658

Jia, W., Li, H., He, Y.W., 2005b. The extracellular matrix protein mindin serves as an integrin ligand and is critical for inflammatory cell recruitment. Blood 106, 3854-3859. https://doi.org/10.1182/blood-2005-04-1658

Jin, C., Lin, J.R., Ma, L., Song, Y., Shi, Y.X., Jiang, P., Dong, Y., Li, X.S., 2017. Elevated spondin-2 expression correlates with progression and prognosis in gastric cancer. Oncotarget 8, 10416-10424. https://doi.org/10.18632/oncotarget.14423

Kang, H.-G., Kim, W.-J., Noh, M.-G., Chun, K.-H., Kim, S.-J., 2020. SPON2 Is Upregulated through Notch Signaling Pathway and Promotes Tumor Progression in Gastric Cancer. Cancers (Basel). 12, 1439. https://doi.org/10.3390/cancers12061439

Kim, D., Paggi, J.M., Park, C., Bennett, C., Salzberg, S.L., 2019. Graph-based genome alignment and genotyping with HISAT2 and HISAT-genotype. Nat. Biotechnol. 37, 907915. https://doi.org/10.1038/s41587-019-0201-4

Koster, M.I., Kim, S., Roop, D.R., 2005. P63 deficiency: a failure of lineage commitment or stem cell maintenance? J. Investig. Dermatol. Symp. Proc. https://doi.org/10.1111/j.1087-0024.2005.200416.x

Krebsbach, P.H., Villa-Diaz, L.G., 2017. The Role of Integrin a6 (CD49f) in Stem Cells: More than a Conserved Biomarker. Stem Cells Dev. 26, 1090-1099. https://doi.org/10.1089/scd.2016.0319

Kröger, C., Afeyan, A., Mraz, J., Eaton, E.N., Reinhardt, F., Khodor, Y.L., Thiru, P., Bierie, B., Ye, X., Burge, C.B., Weinberg, R.A., 2019. Acquisition of a hybrid E/M state is essential for tumorigenicity of basal breast cancer cells. Proc. Natl. Acad. Sci. U. S. A. 116, 7353-7362. https://doi.org/10.1073/pnas.1812876116

Lapidot, T., Sirard, C., Vormoor, J., Murdoch, B., Hoang, T., Caceres-Cortes, J., Minden, M., Paterson, B., Caligiuri, M.A., Dick, J.E., 1994. A cell initiating human acute myeloid leukaemia after transplantation into SCID mice. Nature 367, 645-648. https://doi.org/10.1038/367645a0

Li, Y., Kong, D., Ahmad, A., Bao, B., Sarkar, F.H., 2013. Pancreatic cancer stem cells: Emerging target for designing novel therapy. Cancer Lett. https://doi.org/10.1016/j.canlet.2012.03.018

Li, Y., Wang, Z., Ajani, J.A., Song, S., 2021. Drug resistance and Cancer stem cells. Cell Commun. Signal. https://doi.org/10.1186/s12964-020-00627-5

Love, M.I., Huber, W., Anders, S., 2014. Moderated estimation of fold change and dispersion for RNA-seq data with DESeq2. Genome Biol. 15, 550. https://doi.org/10.1186/s13059014-0550-8

Lucarelli, G., Rutigliano, M., Bettocchi, C., Palazzo, S., Vavallo, A., Galleggiante, V., Trabucco, S., Di Clemente, D., Selvaggi, F.P., Battaglia, M., Ditonno, P., 2013a. Spondin-2, a secreted extracellular matrix protein, is a novel diagnostic biomarker for prostate cancer. J. Urol. 190, 2271-2277. https://doi.org/10.1016/j.juro.2013.05.004

Lucarelli, G., Rutigliano, M., Bettocchi, C., Palazzo, S., Vavallo, A., Galleggiante, V., Trabucco, S., Di Clemente, D., Selvaggi, F.P., Battaglia, M., Ditonno, P., 2013b. 
Spondin-2, a secreted extracellular matrix protein, is a novel diagnostic biomarker for prostate cancer. J. Urol. 190, 2271-2277. https://doi.org/10.1016/j.juro.2013.05.004

Ma, S.Y., Park, J.H., Hana, J., Ha, S.M., Kim, Y., Park, D.H., Lee, D.H., Lee, S., Chu, I.H., Jung, S.Y., Kim, I.H., Choi, I.W., Choi, C.S., Park, S., 2017. Snail maintains metastatic potential, cancer stemlike properties, and chemoresistance in mesenchymal mouse breast cancer TUBO-P2J cells. Oncol. Rep. 38, 1867-1876.

https://doi.org/10.3892/or.2017.5834

Mani, S. a, Guo, W., Liao, M., Eaton, E.N., Zhou, A.Y., Brooks, M., Reinhard, F., Zhang, C.C., Campbell, L.L., Polyak, K., Brisken, C., Yang, J., Weinberg, R. a, 2009. EpithelialMesenchymal Transition Generates Cells Which Have Stem Cell Properties. Cell 133, 704-715. https://doi.org/10.1016/j.cell.2008.03.027.The

Matsui, W.H., 2016. Cancer stem cell signaling pathways. Med. (United States). https://doi.org/10.1097/MD.0000000000004765

Meng, F., Lowell, C.A., 1998. A $\beta 1$ integrin signaling pathway involving Src-family kinases, $\mathrm{Cbl}$ and $\mathrm{Pl}-3$ kinase is required for macrophage spreading and migration. EMBO J. 17, 4391-4403. https://doi.org/10.1093/emboj/17.15.4391

Michor, F., Polyak, K., 2010. The origins and implications of intratumor heterogeneity. Cancer Prev. Res. https://doi.org/10.1158/1940-6207.CAPR-10-0234

Murray, S.A., Gridley, T., 2006. Snail1 gene function during early embryo patterning in mice. Cell Cycle. https://doi.org/10.4161/cc.5.22.3502

Ni, H., Ni, T., Feng, J., Bian, T., Liu, Y., Zhang, J., 2019. Spondin-2 is a novel diagnostic biomarker for laryngeal squamous cell carcinoma. Pathol. Res. Pract. 215, 286-291. https://doi.org/10.1016/j.prp.2018.11.017

Nowak, J.A., Fuchs, E., 2009. Isolation and culture of epithelial stem cells. Methods Mol. Biol. 482, 215-232. https://doi.org/10.1007/978-1-59745-060-7_14

Pastushenko, I., Blanpain, C., 2019. EMT Transition States during Tumor Progression and Metastasis. Trends Cell Biol. https://doi.org/10.1016/j.tcb.2018.12.001

Phi, L.T.H., Sari, I.N., Yang, Y.G., Lee, S.H., Jun, N., Kim, K.S., Lee, Y.K., Kwon, H.Y., 2018. Cancer stem cells (CSCs) in drug resistance and their therapeutic implications in cancer treatment. Stem Cells Int. https://doi.org/10.1155/2018/5416923

Plaks, V., Kong, N., Werb, Z., 2015. The cancer stem cell niche: How essential is the niche in regulating stemness of tumor cells? Cell Stem Cell.

https://doi.org/10.1016/j.stem.2015.02.015

Plikus, M. V., Guerrero-Juarez, C.F., Treffeisen, E., Gay, D.L., 2015. Epigenetic control of skin and hair regeneration after wounding. Exp. Dermatol. 24, 167-170. https://doi.org/10.1111/exd.12488

Raz, R., Lee, C.-K., Cannizzaro, L.A., D'eustachio, P., Levy, D.E., 1999. Essential role of STAT3 for embryonic stem cell pluripotency (leukemia inhibitory factorcytokine signalingJAK-STAT pathwayembryonic stem cell differentiation), Cell Biology.

Rébé, C., Végran, F., Berger, H., Ghiringhelli, F., Georges, C., Leclerc, F., Médecine, F. De, Bourgogne, U. De, 2013. A key factor in tumor immunoescape STAT3 activation 1-10.

Scheel, C., Eaton, E.N., Li, S.H.J., Chaffer, C.L., Reinhardt, F., Kah, K.J., Bell, G., Guo, W., Rubin, J., Richardson, A.L., Weinberg, R.A., 2011. Paracrine and autocrine signals induce and maintain mesenchymal and stem cell states in the breast. Cell 145, 926940. https://doi.org/10.1016/j.cell.2011.04.029 
bioRxiv preprint doi: https://doi.org/10.1101/2021.06.26.450022 this version posted June 29, 2021. The copyright holder for this preprint (which was not certified by peer review) is the author/funder, who has granted bioRxiv a license to display the preprint in perpetuity. It is made available under aCC-BY-NC-ND 4.0 International license.

Schober, M., Fuchs, E., 2011. Tumor-initiating stem cells of squamous cell carcinomas and their control by TGF- $\beta$ and integrin/focal adhesion kinase (FAK) signaling. Proc. Natl. Acad. Sci. U. S. A. 108, 10544-10549. https://doi.org/10.1073/pnas.1107807108

Simon, I., Liu, Y., Krall, K.L., Urban, N., Wolfert, R.L., Kim, N.W., McIntosh, M.W., 2007. Evaluation of the novel serum markers B7-H4, Spondin 2, and DcR3 for diagnosis and early detection of ovarian cancer. Gynecol. Oncol. 106, 112-118. https://doi.org/10.1016/j.ygyno.2007.03.007

Smith, B.N., Burton, L.J., Henderson, V., Randle, D.D., Morton, D.J., Smith, B.A., TaliaferroSmith, L., Nagappan, P., Yates, C., Zayzafoon, M., Chung, L.W.K., Odero-Marah, V.A., 2014. Snail Promotes Epithelial Mesenchymal Transition in Breast Cancer Cells in Part via Activation of Nuclear ERK2. PLoS One 9, e104987. https://doi.org/10.1371/journal.pone.0104987

Somasundaram, R., Villanueva, J., Herlyn, M., 2012. Intratumoral Heterogeneity as a Therapy Resistance Mechanism. Role of Melanoma Subpopulations, in: Advances in Pharmacology. Academic Press Inc., pp. 335-359. https://doi.org/10.1016/B978-0-12397927-8.00011-7

Straussman, R., Morikawa, T., Shee, K., Barzily-Rokni, M., Qian, Z.R., Du, J., Davis, A., Mongare, M.M., Gould, J., Frederick, D.T., Cooper, Z.A., Chapman, P.B., Solit, D.B., Ribas, A., Lo, R.S., Flaherty, K.T., Ogino, S., Wargo, J.A., Golub, T.R., 2012. Tumour micro-environment elicits innate resistance to RAF inhibitors through HGF secretion. Nature 487, 500-504. https://doi.org/10.1038/nature11183

Sun, H.R., Wang, S., Yan, S.C., Zhang, Y., Nelson, P.J., Jia, H.L., Qin, L.X., Dong, Q.Z., 2019. Therapeutic strategies targeting cancer stem cells and their microenvironment. Front. Oncol. 9, 1104. https://doi.org/10.3389/fonc.2019.01104

Tan, T.Z., Miow, Q.H., Miki, Y., Noda, T., Mori, S., Huang, R.Y., Thiery, J.P., 2014. Epithelial-mesenchymal transition spectrum quantification and its efficacy in deciphering survival and drug responses of cancer patients. EMBO Mol. Med. 6, 12791293. https://doi.org/10.15252/emmm.201404208

Tao, G., Levay, A.K., Gridley, T., Lincoln, J., 2011. Mmp15 is a direct target of Snai1 during endothelial to mesenchymal transformation and endocardial cushion development. Dev. Biol. 359, 209-221. https://doi.org/10.1016/j.ydbio.2011.08.022

Tellez-Gabriel, M., Ory, B., Lamoureux, F., Heymann, M.F., Heymann, D., 2016. Tumour heterogeneity: The key advantages of single-cell analysis. Int. J. Mol. Sci. https://doi.org/10.3390/ijms17122142

Wang, H., Unternaehrer, J.J., 2019. Epithelial-mesenchymal Transition and Cancer Stem Cells: At the Crossroads of Differentiation and Dedifferentiation. Dev. Dyn. https://doi.org/10.1002/dvdy.24678

Wu, J., Gao, W., Tang, Q., Yu, Y., You, W., Wu, Z., Fan, Y., Zhang, L., Wu, C., Han, G., Zuo, X., Zhang, Yao, Chen, Z., Ding, W., Li, X., Lin, F., Shen, H., Tang, J., Zhang, Yaqin, Wang, X., 2021. M2 Macrophage-Derived Exosomes Facilitate HCC Metastasis by Transferring aM $\beta 2$ Integrin to Tumor Cells. Hepatology 73, 1365-1380. https://doi.org/10.1002/hep.31432

Xue, Z.-H., Zhao, C.-Q., Chua, G.-L., Tan, S.-W., Tang, X.-Y., Wong, S.-C., Tan, S.-M., 2010. Integrin $\alpha M \beta 2$ Clustering Triggers Phosphorylation and Activation of Protein Kinase C $\delta$ that Regulates Transcription Factor Foxp1 Expression in Monocytes . J. Immunol. 184, 3697-3709. https://doi.org/10.4049/jimmunol.0903316

Yang, L., Shi, P., Zhao, G., Xu, J., Peng, W., Zhang, J., Zhang, G., Wang, X., Dong, Z., 
Chen, F., Cui, H., 2020. Targeting cancer stem cell pathways for cancer therapy. Signal Transduct. Target. Ther. https://doi.org/10.1038/s41392-020-0110-5

Yang, S.W., Zhang, Z.G., Hao, Y.X., Zhao, Y.L., Qian, F., Shi, Y., Li, P.A., Liu, C.Y., Yu, P.W., 2017. HIF-1a induces the epithelial-mesenchymal transition in gastric cancer stem cells through the Snail pathway. Oncotarget 8, 9535-9545. https://doi.org/10.18632/oncotarget.14484

Ye, F., Zhong, X., Qiu, Y., Yang, L., Wei, B., Zhang, Z., Bu, H., 2017. CD49f can act as a biomarker for local or distant recurrence in breast cancer. J. Breast Cancer 20, 142149. https://doi.org/10.4048/jbc.2017.20.2.142

Yu, Y., 2012. The role of cancer stem cells in relapse of solid tumors. Front. Biosci. E4, 1528. https://doi.org/10.2741/478

Yuan, X., Bian, T., Liu, J., Ke, H., Feng, J., Zhang, Q., Qian, L., Li, X., Liu, Y., Zhang, J., 2017. Spondin2 is a new prognostic biomarker for lung adenocarcinoma. Oncotarget 8 , 59324-59332. https://doi.org/10.18632/oncotarget.19577

Zhang, Q., Wang, X.Q., Wang, J., Cui, S.J., Lou, X.M., Yan, B., Qiao, J., Jiang, Y.H., Zhang, L.J., Yang, P.Y., Liu, F., 2015. Upregulation of spondin-2 predicts poor survival of colorectal carcinoma patients. Oncotarget 6, 15095-15110.

https://doi.org/10.18632/oncotarget.3822

Zhang, X., Yue, P., Page, B.D.G., Li, T., Zhao, W., Namanja, A.T., Paladino, D., Zhao, J., Chen, Y., Gunning, P.T., Turkson, J., 2012. Orally bioavailable small-molecule inhibitor of transcription factor Stat3 regresses human breast and lung cancer xenografts. Proc. Natl. Acad. Sci. U. S. A. 109, 9623-9628. https://doi.org/10.1073/pnas.1121606109

Zhao, G., Kim, K.Y., Zheng, Z., Oh, Y., Yoo, D.S., Lee, M.E., Chung, K.Y., Roh, M.R., Jin, Z., 2020. AXIN2 and SNAIL expression predict the risk of recurrence in cutaneous squamous cell carcinoma after Mohs micrographic surgery. Oncol. Lett. 19, 2133-2140. https://doi.org/10.3892/ol.2020.11324

Zheng, M., Jiang, Y.P., Chen, W., Li, K. De, Liu, X., Gao, S.Y., Feng, H., Wang, S.S., Jiang, J., Ma, X.R., Cen, X., Tang, Y.J., Chen, Y., Lin, Y.F., Tang, Y.L., Liang, X.H., 2015. Snail and slug collaborate on EMT and tumor metastasis through mir-101-mediated EZH2 axis in oral tongue squamous cell carcinoma. Oncotarget 6, 6797-6810. https://doi.org/10.18632/oncotarget.3180

Zhou, W., Lv, R., Qi, W., Wu, D., Xu, Y., Liu, W., Mou, Y., Wang, L., 2014. Snail contributes to the maintenance of stem cell-like phenotype cells in human pancreatic cancer. PLoS One 9. https://doi.org/10.1371/journal.pone.0087409

Zhu, L.F., Hu, Y., Yang, C.C., Xu, X.H., Ning, T.Y., Wang, Z.L., Ye, J.H., Liu, L.K., 2012. Snail overexpression induces an epithelial to mesenchymal transition and cancer stem cell-like properties in SCC9 cells. Lab. Investig. 92, 744-752. https://doi.org/10.1038/labinvest.2012.8

Zou, S., Tong, Q., Liu, B., Huang, W., Tian, Y., Fu, X., 2020. Targeting stat3 in cancer immunotherapy. Mol. Cancer 19, 1-19. https://doi.org/10.1186/s12943-020-01258-7 